Bundesgesundheitsbl 2018 $\cdot 61: 1170-1186$ https://doi.org/10.1007/s00103-018-2791-2 c) Springer-Verlag GmbH Deutschland, ein Teil von Springer Nature 2018

\section{Electronic supplementary material}

The online version of this article (https:// doi.org/10.1007/s00103-018-2791-2) contains supplementary material, which is available to authorized users.

In June 2018 the German Standing Committee on Vaccination (STIKO) endorsed the following recommendation:

The STIKO recommends vaccination of boys aged 9-14 years against human papillomavirus (HPV). Immunization should take place before the first sexual contact. Like HPV vaccination for girls, two vaccine doses at least 5 months apart are needed at the age of 9-14 years. If the first HPV vaccine dose is given at the age of 15 years or older, three vaccine doses are needed. Catch-up vaccination should take place up to the age of 17 years. The aim of vaccinating girls and boys is to reduce the disease burden of HPV-associated tumours.

This paper presents the scientific background of this recommendation, includ-

A. Takla and M. Wiese-Posselt share first authorship.

Anja Takla $\cdot$ Miriam Wiese-Posselt ${ }^{1} \cdot$ Thomas Harder $^{1} \cdot$ Jörg J. Meerpohl ${ }^{2} \cdot$ Marianne Röbl-Mathieu ${ }^{3} \cdot$ Martin Terhardt $^{4} \cdot$ Marianne van der Sande ${ }^{5}$. Ole Wichmann ${ }^{1} \cdot$ Fred Zepp ${ }^{6} \cdot$ Stefanie J. Klug ${ }^{7}$

${ }^{1}$ Immunization Unit, Robert Koch Institute, Berlin, Germany

${ }^{2}$ Institute for Evidence in Medicine (for Cochrane Germany Foundation), Medical Center, University of Freiburg, Freiburg, Germany

${ }^{3}$ Private practice for gynecology/obstetrics, Munich, Germany

${ }^{4}$ Pediatric private practice, Berlin, Germany

${ }^{5}$ Department of Public Health, Institute of Tropical Medicine, Antwerp, Belgium

${ }^{6}$ Center for Pediatric and Adolescent Medicine, University Medical Center Mainz, Mainz, Germany

${ }^{7}$ Department of Epidemiology, Faculty of Sport and Health Sciences, Technical University Munich, Munich, Germany

\title{
Background paper for the recommendation of HPV vaccination for boys in Germany
}

ing the results of literature reviews and the grading of the quality of the available evidence. A German version of this paper is available in the Epidemiologische Bulletin 26/2018 [1].

\section{Introduction}

Infections with human papillomaviruses (HPVs) are common among women and men [2]. HPV infections are thought to be among the most common sexually transmitted infections. Most sexually active individuals are infected with HPV at least once in their lifetimes. Usually it is a transient infection that is undetectable after 1-2 years [3]. However, HPV infection can persist and lead to precancerous lesions and squamous cell carcinoma in the anogenital region or in the oral cavity and pharynx [4-9]. Cervical cancer is the most common manifestation among women, and nearly $100 \%$ of cases are caused by HPV [10]. Each year, around 4600 women in Germany develop a new cervical cancer, and around 1600 die each year of this cancer [11]. Cancer of the vulva, vagina, anus, oral cavity, and pharynx also occur in women, which are attributable to HPV to varying degrees [12-15].
Since 2007, the STIKO recommended HPV vaccination for girls, with the aim of reducing the disease burden of cervical cancer and its precancerous lesions [16]. However, vaccination uptake among girls is limited, with only $42.5 \%$ of 17 -year-old girls being fully vaccinated against $\mathrm{HPV}$ in 2014 [17]. This number rose only slightly in 2015 (44.6\% of 17-year-olds) [18].

In men, the types of cancer attributable to HPV include cancer of the penis and anus, as well as squamous cell carcinoma of the oral cavity and pharynx. It must also be noted that only a certain percentage of each of these cancers is attributable to HPV infection. Using numbers of cancer cases for men by the German Centre for Cancer Registry Data (Zentrum für Krebsregisterdaten, ZfKD; [19]) at the Robert Koch Institute (RKI), around 600 new cases of anal carcinoma, at least 250 new cases of penile carcinoma, and at least 750 new cases of carcinoma of the oral cavity and pharynx that are associated with HPV infection (HPV-attributable carcinoma) occur each year. Epidemiological studies from countries with schoolbased vaccination programmes and thus high rates of HPV vaccination coverage among girls (70-85\%), such as Australia, 
show that herd immunity can significantly reduce the incidence of HPV infection and HPV-attributable lesions in the anogenital region among HPV-unvaccinated boys and men [20]. Because the HPV vaccination rate among girls in Germany is below $50 \%$, it must be assumed that no solid herd immunity can be established in this country in the foreseeable future. In addition, men who have sex with men (MSM) do not benefit from the vaccination of girls against HPV. It was therefore necessary to investigate expanding HPV vaccination to include males.

The STIKO has carefully considered the issue of HPV vaccination of boys. This background paper is the basis for the STIKO decision on this subject. Based on the STIKO standard operating procedure (SOP) for the systematic development of vaccination recommendations, the disease burden of HPV-attributable tumours in men in Germany was estimated, a systematic review of the efficacy and safety of $\mathrm{HPV}$ vaccination in men was conducted, potential epidemiological effects of HPV vaccination for boys on HPV epidemiology and HPV-attributable diseases among the population in Germany were modelled, and a health economics analysis was performed. Furthermore, aspects of practicability and acceptance of the HPV vaccination of boys, as well as an evaluation of the new vaccination recommendation, were discussed.

\section{Pathogen and symptoms}

The prevalence of HPV has been documented worldwide. These viruses are transmitted via direct contact from one person to another, and primarily infect squamous cells. If the anogenital region is infected with HPV, transmission occurs via sexual intercourse; transmission to the oral cavity or oropharynx is possibly via orogenital sexual contact. The use of condoms does not reliably prevent HPV infection $[21,22]$. HPV penetrates the skin or mucous membranes via microinjuries and infects the epithelial cells of the basal layer [4].

\subsection{Aetiology and pathogenesis}

HPVs are non-enveloped DNA viruses. The DNA is double-stranded and is surrounded by a capsule consisting of two different proteins, capsule proteins L1 and L2, both of which are important from an immunological perspective [23]. To date, around 200 different HPV genotypes have been identified. HPVs are subdivided into five genera: alpha, beta, gamma, mu, and nu HPV. Only HPV from the alpha genus can infect both the skin (cutaneous type) and the mucous membranes (mucosal types) [24]. HPV can also be subdivided into so-called high-risk (HR) and low-risk (LR) types, depending on their oncogenic potential. In cases of persistent HPV infection, the risk increases for coincidental integration of the virus genome into the genetic make-up of the infected epithelial cells. Through activation of their oncoproteins E6 and E7, HR types can lead to the malignant degeneration of infected epithelial cells by interfering with growth-regulating pathways [25]. As this process advances, dysplasia and lesions develop in the affected epithelial area, which can lead to the formation of malignant tumours. In this phase, upregulation of tumour suppressor gene p16 $6^{\text {INK4a }}$ occurs; immunohistochemical verification of this gene is also considered a biomarker for advanced cell lesions [26]. The International Agency for Research on Cancer (IARC) of the World Health Organization (WHO) currently classifies the following 12 HR-HPV types as carcinogenic: 16,18 , $31,33,35,39,45,51,52,56,58$, and 59 [27]. DNA of HR type 16 is most frequently found in HPV-attributable carcinomas, making it the dominant type.

\subsection{Symptoms, risk factors, and treatment options for men}

HPV infections in the anogenital region are common and normally heal without symptoms. The natural course of an HPV infection in men has not been described nearly as precisely as in women [28]. If the HPV infection persists, over the years, cell lesions (dysplasia) and benign and malignant tumours can occur.

\subsubsection{Benign anogenital HPV- associated tumours}

The most frequent HPV-associated disease in the external anogenital region is condylomata acuminata (genital warts). Over $90 \%$ of anal or genital warts are caused by an infection with LR HPV types 6 and 11 [29]. Genital warts first form singular, then later patches of small papules, which continue to grow like papilloma. Treatment depends on the number of lesions and the size and location of the area affected. Adults can self-treat over several weeks with topical creams, salves, or solutions that contain active ingredients such as podophyllotoxin $0.5 \%$, imiquimod $5 \%$, or sinecatechine $10 \%$. Alternatively, ablation therapy can be administered using electrocautery, curettage, or laser therapy. Genital warts can also be removed surgically in layers. A physician can also administer repeated applications of trichloroethanoic acid $80-90 \%$ or cryotherapy [30]. If genital warts are diagnosed and treated, the anogenital region should be inspected for any other HPV-associated intraepithelial neoplasia.

\subsubsection{Malignant anogenital HPV- associated tumours}

In the anogenital region, a persistent HPV infection can trigger penile or anal carcinoma in men.

Penile carcinoma is usually a squamous cell carcinoma. It is a rare type of cancer that mostly affects men of advanced age. In addition to age and HPV infection (with HR HPV types 16 and 18; [27]), other risk factors for penile carcinoma include tobacco consumption, multiple sexual partners, chronic or recurrent inflammation of the penis, phototherapy with ultraviolet rays, poor hygiene, and phimosis $[31,32]$. Diseases of the penis such as balanitis xerotica obliterans are sporadically associated with penile carcinoma. Men who were circumcised as children have a lower risk of developing penile carcinoma [33]. HPV-associated penile carcinoma develops via precancerous lesions, so-called penile intraepithelial neoplasia (PIN, also PeIN according to the new WHO classification), which can be subdivided into three levels depending on their histology (PIN I-III). PIN III are defined as in situ squamous cell carcino- 
ma; their clinical presentations are erythroplasia of Queyrat, penile Bowen's disease, or Bowenoid papulosis [34]. When PIN is diagnosed, conservative treatment options should be considered first. These include the topical administration of imiquimod $5 \%$ or 5 -fluorouracil, electrocautery, curettage, or laser therapy [30,34]. Because these treatment options are limited in their effectiveness, surgical removal of the affected area is often necessary, which can lead to cosmetic and functional impairment of the penis. The severity of penile carcinoma is classified using TNM stages [35]. In the lower TNM stages, primary radiotherapy can be used, possibly combined with the topical use of imiquimod $5 \%$ and/or 5 -fluorouracil. In the higher TNM stages, an initial surgical resection of the penile tumour is conducted, followed by radiation and chemotherapy that is appropriate to the respective TNM stage.

Up to $80 \%$ of cases of anal carcinoma are squamous-cell carcinoma, and 15$20 \%$ of cases are adenocarcinoma [36]. The majority of squamous-cell anal carcinoma cases are caused by the HR HPV types 16,18 , and 33 , [37] i.e. a persistent HPV infection causes the development of epithelial dysplasia on the anus. These lesions, called anal intraepithelial neoplasia (AIN, grade III) are precancerous lesions that can develop into anal carcinoma if not treated. Ablative and minimally invasive surgical procedures such as curettage, excision, coagulating procedures, cryotherapy, or laser treatment are used to treat AIN [30]. Risk factors for the occurrence of anal carcinoma are receptive anal intercourse, immunodeficiency or immunosuppression (including HIV positivity), multiple sexual partners, and tobacco consumption. Often the initial diagnosis of anal carcinoma is coincidental. There is no organized cancer screening programme for anal carcinoma in Germany [38]. AIN or early stage anal carcinoma presents as rough verrucous papules with relatively few symptoms. Classification and treatment of the clinical status of anal carcinoma is performed using the TNM criteria [35]. Primary surgical removal should be carried out only if the tumour is small and local $(<1 \mathrm{~cm}, \mathrm{~T} 1, \mathrm{~N} 0)$; maintaining the function of the anal sphincter is a primary concern [39]. Combined radiochemotherapy is recommended for more extensive findings. A radical surgical resection of the tumour and removal of the lymph nodes is suggested only for more severe findings, and usually necessitates the use of a colostoma.

\subsubsection{Malignant oropharyngeal HPV-associated tumours}

$\mathrm{HPV}$-associated malignant tumours of the head and neck region include in particular squamous-cell carcinoma of the oropharynx (ICD-10 C10), the tonsils (C09), and the base of the tongue (C01), which are summarized as oropharyngeal carcinoma [40]. A correlation between HPV infection (in particular HR HPV type 16) and the development of tumours has been demonstrated with sufficient evidence for these three tumour localizations [5]. HPV-associated carcinomas in other regions of the oral cavity, pharynx, and larynx are described in the literature. In addition to a persistent HPV infection (mostly with HPV 16), tobacco and alcohol consumption are substantial risk factors for cancer [41]. It must be noted that only some oropharyngeal carcinomas are HPV-attributable (see also section 3.2). Verification of HPV DNA and the expression of biomarkers such as HPV E6/E7 mRNA transcripts or the tumour suppressor gene CDKN2A (p16 $6^{\text {INK4a }}$ ) are being increasingly used for the primary diagnosis of oropharyngeal carcinoma, because evidence of HPV positivity has major implications on the prognosis. In the 8th edition of the TNM classification of malignant tumours, p16-positive and -negative oropharyngeal carcinoma is classified into various stages [42], necessitating the routine examination of these tumours for HPV association. However, this diagnostic step is not an integral part of the current AWMF (The Association of the Scientific Medical Societies) guideline for carcinoma of the oral cavity [43]. It has been observed that patients with HPV-positive oropharyngeal carcinoma have markedly longer survival times than those with HPV-negative tumours [4446]. The risk of mortality for patients with HPV-positive oropharyngeal carcinoma is $58 \%$ lower than that of patients with an HPV-negative tumour [47]. Treatment for oropharyngeal carcinoma is adjusted according to the respective stage, and includes primary surgery and primary radiation therapy. Surgical interventions and subsequent radiation therapy can lead to extensive destruction of areas of the pharynx and larynx, often resulting in swallowing and speech dysfunction and necessitating surgical reconstruction.

\section{Epidemiology}

Around $16 \%$ of all cancers worldwide are caused by infections; in developed countries, this rate is $7 \%$, half of which are HPV-attributable [48]. The development of a carcinoma as a consequence of a persistent HPV infection is a rare event [4]. This was described using clinical observations of the natural course of HPV infections in the cervix: around $10 \%$ of incident HPV infections persist longer than 12-24 months, thus causing higher-grade cervical precancerous lesions, so-called cervical intraepithelial neoplasia (CIN III). If these lesions are not treated, around 50\% of these cases could lead to cervical cancer within the following 10-30 years [6]. To date, no such conclusions on tumour development in cases of persistent HPV infection have been reached for HPV infections in men. HPV positivity in cases of oropharyngeal carcinoma [49] is more frequent in younger patients (compared with patients with HPV negative tumours) and in cases of anal, penile or oropharyngeal carcinoma in persons with known risk factors for persistent HPV infection, such as multiple sex partners, homosexual contacts, oral or anal intercourse, and immunosuppression or immunodeficiency (including HIV). Tobacco and alcohol consumption in particular are risk factors for the development of HPV-negative oropharyngeal carcinoma [50]. Because HPV infections in the sexually active population are frequent, HPV-attributable carcinoma causes a notable disease burden if HPV vaccinations are not administered $[4,48]$. The IARC most recently updated and published its classification of carcinogenic HPV types in June 2017 [27]. A list of HPV types according to cancer localization is provided in $\bullet$ Table 1.

For the description of HPV-associated cancer epidemiology, it is essential 
Table 1 Classification of carcinogenic high-risk HPV types by the WHO International Agency for Research on Cancer (IARC), updated 2017 [27]

\begin{tabular}{|c|c|c|}
\hline \multirow[t]{2}{*}{ Carcinoma localization } & \multicolumn{2}{|c|}{ High-risk HPV types classified as carcinogenic by IARC: } \\
\hline & $\begin{array}{l}\text { Classification with sufficient } \\
\text { evidence }\end{array}$ & $\begin{array}{l}\text { Classification with limited } \\
\text { evidence }\end{array}$ \\
\hline Oral cavity & HPV 16 & HPV 18 \\
\hline Tonsils & HPV 16 & ----- \\
\hline Pharynx & HPV 16 & ----- \\
\hline Larynx & ----- & HPV 16 \\
\hline Anus & HPV 16 & HPV 18, 33 \\
\hline Penis & HPV 16 & HPV 18 \\
\hline Vulva & HPV 16 & HPV 18, 33 \\
\hline Vagina & HPV 16 & ----- \\
\hline Cervix uteri & $\begin{array}{l}\text { HPV } 16,18,31,33,35,39,45 \\
51,52,56,58,59\end{array}$ & $\begin{array}{l}\text { HPV } 26,53,66,67,68,70,73 \text {, } \\
82\end{array}$ \\
\hline
\end{tabular}

to define the HPV-attributable proportion for each type of cancer. Tumour tissue has been examined worldwide for the presence of HPV DNA, and in part also for the presence of the biomarkers E6/E7 mRNA and/or $\mathrm{p} 16^{\mathrm{INK} 4 \mathrm{a}}$ [51]. The percentage of HPV-associated carcinoma differs according to geographical region. The data for Europe is referenced hereinafter. For anal carcinoma, similar HPV prevalence has been detected in tumour tissues in various studies. In one meta-analysis, the percentage of HPV-associated anal carcinoma was $84.2 \%$ [14], and was similarly $87.6 \%$ in one international cross-sectional study [14, 52]. For penile carcinoma, an HPV prevalence of $46.7 \%$ was recorded in one meta-analysis; [53] this percentage was $32.2 \%$ in a larger international cross-sectional study of more than 1000 cases from the years 1983-2011 [54]. There are a number of possible reasons for the difference between these two numbers. Various smaller studies employing different laboratory methods were included in the meta-analysis by Miralles-Guri and colleagues. Furthermore, country-specific variability has been described for the $\mathrm{HPV}$-associated percentage of penile carcinoma and, in both publications, tumour tissue partly from various countries was examined. HPV prevalence also depends on the histology of the penile carcinoma. Finally, different fixation techniques were used, possibly resulting in underestimation in paraffin-embedded samples.
The data basis for determining the HPV-associated percentage of oropharyngeal carcinoma is especially complex. One reason for this is that, to date, studies have examined tumour tissue from various anatomical locations, in some cases including samples of laryngeal carcinoma. Another reason is the use of different detection methods. In some studies, only detection of HPV DNA was conducted, but in others, additional tests for the biomarkers E6/E7 mRNA and/or p16 ${ }^{\mathrm{INK} 4 \mathrm{a}}$ were included in the assessment. Furthermore, the percentage of HPV-associated oropharyngeal carcinoma differs around the world according to geographical region, frequency and intensity of tobacco and alcohol consumption, and tumour histology. The geographical diversity is particularly remarkable: observational studies showed that the percentage of HPV-16-positive oropharyngeal squamous-cell carcinoma is $60 \%$ in the USA, $31 \%$ in Europe, and only $4 \%$ in Brazil [55]. HPV prevalence of $41.3 \%$ in Europe and $45.8 \%$ worldwide has been reported in two meta-analyses for oropharyngeal carcinoma $[51,56]$. HPV DNA or in $22.3 \%$ and $15.9 \%$ of all oropharyngeal carcinoma cases, respectively, in a larger cross-sectional study [15].

HPV prevalence from meta-analyses and cross-sectional studies (using tumour tissue embedded in paraffin) were cited to estimate the HPV-associated percentages HPV DNA plus biomarkers were verified of the various cancers. An overview is provided in $\bullet$ Table 2.

\subsection{Incidence and prevalence of HPV infections in the male population}

Incident HPV infections in the anogenital area in men are frequent; the majority of these incident infections heal on their own (so-called clearance). A systematic review from 2006 on the anogenital HPV prevalence in men showed a broad range of prevalence. The reason for this was proposed to be that various swab locations, tissue gathering techniques, and HPV assays were used [57]. In a large population-based survey in the USA $(n=2046)$ covering 2013-2014, a penile HPV prevalence of $42.2 \%$ (95\% CI 38.3-46.1) and HR HPV type prevalence of $23.4 \%$ (95\% CI 21.3-25.6) was recorded [58]. A lower prevalence was observed among younger age groups than older age groups. The prevalence was significantly lower in the 14- to 19-year-old age group than in the other age groups, with a prevalence of 12.5\% (95\% CI 10.0-15.6) for all HPV types and 7.3\% (5.4-9.9) for HR HPV types. This highlights the indirect effects of HPV vaccination of girls implemented in the USA since 2006 (see section 9). In the age group of 20- to 24-year-olds, the prevalence for all HPV types was below $40 \%$; in all men $>24$ years, the penile prevalence of HPV was stable across all age groups at over $45 \%$, and at $23 \%$ to just under $30 \%$ for HR HPV types. Therefore, unlike women, who exhibit peak prevalence of HPV in the unvaccinated population at the age of 15-29 years, men exhibit a high prevalence of genital HPV regardless of age [59]. This was confirmed in a recent meta-analysis of HPV incidence in the anogenital and oral region [60]. In this work, it also became clear that HPV 16 is the most frequent type for incident and persistent infections, and that clearance (spontaneous healing) of an incident HPV infection occurs more frequently in men than in women. The incidence of anal HPV infection among MSM (HIV positive and negative) is high at 21.3-46.2/100 person-years (PY) in comparison to 7.9 9.7/100 PY among heterosexual men (regardless of HIV status). The clearance of 
Table 2 HPV prevalence (evidence of HPV DNA) in anal, penile, and oropharyngeal carcinoma. The tumour tissue samples were taken from patients in Europe

\begin{tabular}{|c|c|c|c|}
\hline $\begin{array}{l}\text { Cancer } \\
\text { (ICD-10 code) }\end{array}$ & Study/reference & $\begin{array}{l}\text { Number of sam- } \\
\text { ples from Europe }\end{array}$ & $\begin{array}{l}\text { HPV prevalence } \\
\text { in } \%\end{array}$ \\
\hline \multirow[t]{2}{*}{$\begin{array}{l}\text { Anal carcinoma } \\
\text { (C21) }\end{array}$} & $\begin{array}{l}\text { Meta-analysis including } 13 \\
\text { studies; } \\
\text { De Vuyst et al., 2009 [52] }\end{array}$ & $696^{a}$ & $84.2 \%$ \\
\hline & $\begin{array}{l}1 \text { study testing tumour tissue } \\
\text { embedded in paraffin; } \\
\text { Alemany et al., } 2015 \text { [14] }\end{array}$ & $169^{a}$ & $87.6 \%$ \\
\hline \multirow[t]{2}{*}{$\begin{array}{l}\text { Penile carcinoma } \\
\text { (C60) }\end{array}$} & $\begin{array}{l}\text { Meta-analysis including } 10 \\
\text { studies; } \\
\text { Miralles-Guri et al., } 2009 \text { [53] }\end{array}$ & 463 & $46.7 \%$ \\
\hline & $\begin{array}{l}1 \text { study testing tumour tissue } \\
\text { embedded in paraffin; } \\
\text { Alemany et al., } 2016 \text { [54] }\end{array}$ & 135 & $32.2 \%$ \\
\hline \multirow[t]{2}{*}{$\begin{array}{l}\text { Oropharyngeal } \\
\text { carcinoma }\end{array}$} & $\begin{array}{l}\text { Meta-analysis including } 39 \\
\text { studies; } \\
\text { Abogunrin et al., } 2014 \text { [56] }\end{array}$ & $\begin{array}{l}\text { Oropharynx: } 894^{\mathrm{a}} \\
\text { Tonsils: } 605^{\mathrm{a}} \\
\text { Base of the tongue: } \\
193^{\mathrm{a}}\end{array}$ & $\begin{array}{l}41.3 \%^{c} \\
66.4 \% \\
47.2 \%\end{array}$ \\
\hline & $\begin{array}{l}1 \text { study testing tumour tissue } \\
\text { embedded in paraffin; } \\
\text { Castellsagué et al., 2016 [15] }\end{array}$ & $810^{\mathrm{b}}$ & $22.3 \%$ \\
\hline \multicolumn{4}{|c|}{$\begin{array}{l}{ }^{a} \text { Numbers cannot be allocated according to gender. } \\
{ }^{b} \text { Includes various sublocalizations (e. g. tonsils, base of the tongue, unspecific oropharyngeal localization, soft } \\
\text { palate). } \\
\text { 'The lowest percentage (41.3\%) will be used hereinafter to maintain a conservative estimate. }\end{array}$} \\
\hline
\end{tabular}

anal HPV infections ranged from 14.666.7/100 PY within 30-39 months, depending on the HPV type. Studies from America [61] and Europe have shown that HIV-positive MSM are associated with high HR HPV prevalence. In a Dutch study, the prevalence of anal HR HPV was $45 \%$ among $461 \mathrm{HIV}$-negative MSM, and 65\% among 317 HIV-positive MSM [62]. HPV 16 was verifiable in the anal region of $13 \%$ of the HIV-negative MSM, and of $22 \%$ of the HIV-positive MSM. Studies in Germany have found a similarly high prevalence of anal HPV infections of $42.4 \%$ [63] among 602 HIV-negative MSM (median age 22 years), and a much higher prevalence of $91.5 \%$ among 801 HIV-positive MSM aged 18-80 years [64]. In addition to MSM and HIV-positivity, multiple sex partners, a large number of lifetime sex partners, the presence of other sexually transmitted infections (STIs), immunodeficiency/immunosuppression, and smoking have been identified as risk factors for HPV infection $[65,66]$.

Oral HPV prevalence was described in a systematic review [67]. HPV prevalence does not differ between men and women. HPV was verified in $4.5 \%$ of over 4000 healthy study participants (95\% CI 3.9-5.1), and type HPV 16 was present in $3.5 \%$ of these (95\% CI 3.0-4.1). In another systematic review, it was reported that oral HPV 16 incidence, i. e. the rate of new HPV 16 infections in healthy persons over a period of 12 months, was 4.8\% (95\% CI 3.2-7.3). Furthermore, 43$83 \%$ of oral HPV 16 infections were reported to heal within 7-22 months. Homosexuality and immunodeficiency, in particular HIV-positivity, are also risk factors for oral HPV infections. In a study of 170 MSM, carcinogenic HPV types were verified in the oral cavity of $9.2 \%$ of HIV-negative and $11.1 \%$ of HIV-positive cases [68].

\subsection{Epidemiology of HPV- attributable carcinoma in the male population}

\subsubsection{Penile carcinoma}

In 2013 in Germany, 776 men developed penile carcinoma (C60) (including both HPV-positive and HPV-negative tumours); 170 of which died of this general- ly rare tumour. The age-standardized incidence in Germany is 1.3/100,000 persons, and this rate has been stable in recent years (German Centre for Cancer Registry Data-ZfKD, data effective 07/2017). Predominantly men of advanced age are affected [69]. The relative 5-year survival rate (5YSR) in Europe is $68 \%$. The prognosis depends heavily on the age of the patient and the disease stage at diagnosis [70]. So far it is not clear to what extent verification of HPV in penile carcinoma is associated with a better prognosis and higher probability of survival [71]. With regard to the HPV prevalence in tumour tissues shown in $\bullet$ Table 2 and based on current incidence estimates, it can be assumed that between 250 and 360 new cases of HPV-associated penile carcinoma were diagnosed in Germany in 2013.

\subsubsection{Anal carcinoma}

With regard to HPV-positive and HPV-negative tumours, around 650 men in Germany develop a new case of anal carcinoma each year; in 2013, 164 men died of this type of tumour. The age-standardized incidence of anal carcinoma among men in 2013 was $1.3 / 100,000$, and somewhat higher for women at $1.8 / 100,000$, with around 1100 new cases each year; with increasing trends reported among both genders [72]. Anal carcinoma is thus a rare form of cancer; however, the incidence is markedly higher among persons with an increased risk of persistent HPV infection and/or risk of developing HIV-associated malignant tumours, including MSM, HIV-positive persons, or other persons with immunosuppression [66]. In France, an incidence of 95/100,000 PY was reported for anal carcinoma in HIV-positive MSM, compared with 0.6 in the general male population [73]. With regard to the overall population, the highest incidence of squamous cell carcinoma of the anus since the 2000s was observed in the 45-64 year age groups in various European countries and in the UK, the USA, and Australia [74]. The age-standardized 5YSR in Europe in the 1990s was 51\% [75]; a current evaluation of the United States SEER (Surveillance, Epidemiology, and End Results Program) cancer registry data shows a 5YSR 
between $30 \%$ and $80 \%$ for both genders, depending on the extent, size, and anatomical location of the tumour [76]. HPV prevalence in anal tumour tissues in the various studies was a uniform $84 \%$ [52] to $88 \%$ [14]. This prevalence allows an estimation that around $600 \mathrm{HPV}$-attributable cases of anal carcinoma occur each year among men in Germany.

\subsubsection{Carcinoma of the oral cavity and pharynx}

Around 9450 men and 5700 women develop a tumour in the oral cavity or pharynx each year in Germany (C00-C14) [19]. Among men, 3340 cases are oropharyngeal carcinoma (tumours of the base of the tongue (C01), tonsils (C09), and the oropharynx (C10)), which can often be caused by persistent HPV infection. The percentage of HPV-attributable carcinoma in other localizations of the oropharynx is probably low [77]. Around 1590 men die each year of an oropharyngeal carcinoma (only C01, C09, C10). The average age at disease onset is 64 years, but a younger age was observed for HPV-associated oropharyngeal carcinoma [50]. The age-standardized incidence of oropharyngeal carcinoma is 1.6 per 100,000 inhabitants for C01, 2.6 for C09, and 2.2 for $\mathrm{C} 10$, depending on the diagnosis. The relative 5YSR for all tumours of the oral cavity and pharynx (C00-C14) is 45$46 \%$. These epidemiological numbers refer to all oropharyngeal carcinomas, both HPV positive and negative. A recent publication based on selected cancer registry data in Germany showed that the 5YSR in men with HPV-associated oropharyngeal carcinoma is $45.4 \%$, and thus better than in men with tumours not attributable to HPV (5YSR 40.8\%) [78]. Considerable differences have also been described within oropharyngeal carcinomas: men with tumours of the tonsils (C09) have markedly better survival rates (5YSR 54.6\%) than men who have tumours on the base of the tongue (C01, 5YSR 44.5\%) or who have been diagnosed with oropharyngeal carcinoma (C10, 5YSR 36.3\%). To estimate the HPV-attributable percentage of oropharyngeal carcinoma (C01, C09, C10), the HPV prevalence determined in international studies of tumour tissues must be referenced. If the value record- ed in a large cross-sectional study $(22.3 \%$ HPV prevalence [15]) is taken as the basis, an estimated total of 745 men developed a case of HPV-positive oropharyngeal carcinoma (C01, C09, C10) in Germany in 2013. If the value from meta-analysis is considered (41.3\% HPV prevalence [56], see - Table 2), an estimated 1380 men developed these tumours. These are estimates that can vary depending on the selection of published HPV prevalence rates particularly regarding tumour tissue of the head and neck, the underlying laboratory methods, the selection of tumour sublocalizations, the presence of specific histological types, and the completeness of the registry data. A lower estimate of $836 \mathrm{HPV}$-attributable oropharyngeal carcinoma for men and women has been recently published based on case numbers of the ZfKD [79]. The HPV prevalence reported in the literature cannot be used as the attributable percentage of deaths (see - Table 3) because it is uncertain whether these data can be applied to Germany, and because the prognosis of HPV-attributable oropharyngeal carcinoma differs significantly from that of HPV-negative tumours.

The ZfKD reports that the frequency of oropharyngeal and base of the tongue carcinoma among men in Germany has been generally stable in recent years, but the incidence of tonsil carcinoma continues to rise [19]. Other countries in North America and Europe report the same trend; in some cases the rise in incidence is significant [80-82]. Some studies indicate that the percentage of HPV-attributable oropharyngeal carcinoma has risen in Germany [83, 84]. Epidemiological cancer registry data also show that the classic smoking-associated cancers of the respiratory tract and larynx are becoming markedly rarer in men, but oropharyngeal carcinoma (C01, C09, C10) is not following this trend [85].

\subsection{Epidemiology of condylomata acuminata in the male population}

The most frequent HPV-associated lesions in the outer genital region are condylomata acuminata (genital warts). They are highly infectious; the consistent use of condoms can reduce, but not reliably pre- vent, the transmission of HPV [22]. After an incubation period of 3 weeks to 8 months, typical papules form in the anogenital region. Over $90 \%$ of cases of genital warts are attributable to LR HPV types 6 and 11 [29]. Data from Germany show that genital warts are frequent, with an incidence of 170/100,000 PY for both genders and an estimated lifetime risk of 5-10\% [86]. The incidence is higher among women than among men (191 versus 148/100,000 PY). Men aged 25-29 years of age achieve the highest incidence (457/100,000), with incidence gradually decreasing after that age.

\section{Vaccination aims}

The aim of vaccinating girls and boys at the age of 9-14 years is to reduce the disease burden of HPV-associated tumours.

\section{5. $H P V$ vaccines}

Currently there are two different HPV vaccines available in Germany. The vaccine Cervarix ${ }^{\circledR}$ is a bivalent vaccine against HR HPV types 16 and 18. It was approved in September 2007 for the prevention of premalignant anogenital lesions of the cervix, vulva, vagina, and anus, as well as of cervical and anal carcinoma from the age of 9. The nonavalent vaccine Gardas$\mathrm{il}^{\circ} 9$ provides protection against types 6 , $11,16,18,31,33,45,52$, and 58 . It was approved in mid-2016, and follows the tetravalent Gardasil ${ }^{\varpi}$ (approved September 2006). Gardasil ${ }^{\circ} 9$ is approved for the active immunization of persons 9 years of age and older against malignant precancerous lesions and carcinoma affecting the cervix, vulva, vagina, and anus, and against genital warts.

\section{Efficacy/effectiveness of the HPV vaccination of boys and men}

The evidence for efficacy and safety of the HPV vaccination of men was prepared in a systematic review according to the STIKO SOP for the systematic development of vaccination recommendations [87]. 
Table 3 Case numbers, incidences, and deaths of anal, penile, and oropharyngeal carcinoma, for HPV-positive and -negative tumours. Data are for men in Germany in 2013 [19]

\begin{tabular}{llll}
$\begin{array}{l}\text { Type of cancer/ } \\
\text { tumour localization }\end{array}$ & $\begin{array}{l}\text { Tumour case } \\
\text { numbers } \\
\text { (HPV-positive and } \\
\text { HPV-negative) }\end{array}$ & $\begin{array}{l}\text { Tumour incidence } \\
\text { (HPV-positive and } \\
\text { HPV-negative) } \\
\text { per 100,000 }\end{array}$ & $\begin{array}{l}\text { Tumour deaths } \\
\text { (HPV-positive and } \\
\text { HPV-negative) }\end{array}$ \\
\hline Anus (C21) & 684 & 1.3 & 164 \\
\hline Penis (C60) & 776 & 1.3 & 170 \\
Base of the tongue (C01) & 825 & 1.6 & 393 \\
\hline Tonsils (C09) & 1351 & 2.6 & 276 \\
Oropharynx (C10) & 1164 & 2.2 & 921 \\
Sum & 4800 & ---- & 1924
\end{tabular}

\subsection{Search strategy, inclusion criteria, and data analysis}

The protocol for the systematic review was filed in the Prospective Register for Systematic Reviews (PROSPERO) (registration number CRD42016038965). The systematic review was conducted according to the PRISMA guideline (Preferred Reporting Items for Systematic Reviews and Metaanalyses) [88]. The databases MEDLINE, EMBASE and Cochrane Central Register of Controlled Trials were searched (most recent search date: 18 April 2017). In addition, the clinical study registry ClinicalTrials.gov was searched for unpublished and ongoing studies. The search in electronic databases was supplemented by a manual search in the abstract books of major international HPV congresses (EUROGIN 2016, International HPV Conference 2017) and in the reference listings of all studies and reviews identified.

A study was included in the systematic review if it examined the effectiveness and/or safety of the HPV vaccination of boys or men of any age. The control arm should include boys/men who had either received placebo or were unvaccinated, or who had received a vaccination other than the HPV vaccination. In order to be included, a study had to contain data on at least one of the following clinical endpoints: (1) incident oral infection with an HR HPV type; (2) incident anogenital infection with an HR HPV type; (3) persistent oral infection with an HR HPV type (>6 months); (4) persistent anogenital infection with an HR HPV type ( $>6$ months); (5) Condyloma acuminatum caused by HPV 6 or HPV 11; (6) anal intraepithelial neoplasia (AIN) grade II; (7) AIN grade III or carcinoma; (8) penile intraepithelial neoplasia (PIN) grade II; (9) PIN grade III or carcinoma; (10) squamous-cell carcinoma of the head and neck region, including the oropharynx, larynx, and oral cavity; (11) epithelial dysplasia as a precursor of (10); and (12) any severe adverse event after vaccination.

The analyses were conducted in two subgroups: i) all study participants, regardless of HPV infection status at study begin; ii) study participants who were seronegative and PCR-negative for the relevant HPV types at study begin. No limitations were imposed regarding study setting, publication language, or publication status.

The study data were extracted from the studies and the methodological quality of the studies was assessed. The authors of three studies were contacted to obtain further data and information [89-91].

The Cochrane Risk of Bias tool was mized controlled trials (RCTs [92]); the ROBINS-I tool was used for non-randomized trials [93]. The quality of evidence was assessed for each endpoint examined according to the GRADE (Grading of Recommendations Assessment, Development and Evaluation) method [94, 95].

The extracted data were summarized in tables for evaluation. Relative risks (RR), odds ratios, risk differences, and the respective confidence intervals (95\% CI) were calculated or taken from the publications. Vaccine efficacy/effectiveness (VE) was calculated as (1-RR x 100). No meta-analyses could be conducted because used to assess the risk of bias in rando- only one study was identified per endpoint and study design.

\subsection{Characteristics of the studies included and risk of bias}

5196 entries were identified in databases and registries in the systematic literature search, and 7 studies included in the end. Four RCTs and three non-randomized trials were included; these covered a total of 5294 study participants [89, 90, 96-99]. One RCT was a substudy of another trial but reported other endpoints [97, 98]. Table $1^{*}$ in the online annex shows the most important study characteristics. The age of the study participants was 12 to 76 years. The quadrivalent vaccine (Gardas$\mathrm{il}^{\circledR}$ ) was used in all seven studies. None of the studies reported data on the endpoints squamous-cell carcinoma of the head and neck region or epithelial dysplasia as a precursor to squamous-cell carcinoma of the head and neck region.

Three of the RCTs included had a low risk of bias; the other RCT had a high risk of bias [96]. All three non-randomized studies had a high risk of bias.

\subsection{Vaccine efficacy/effectiveness against HPV infections}

Table $2^{\star}$ (see online annex) summarizes the data on VE against HPV infections, regardless of HPV infection status at study begin. The VE against incident anogenital infections through HPV 16 (28\%) [97] and HPV 18 (33.9\%) [97] was low. Greater efficacy (with overlapping 95\% CIs) was found against incident anal infections (45.1\% against HPV 16; 49.5\% against HPV 18) [98]. The estimates of VE against persistent anogenital and anal infections were higher than those against incident infections (46.9\% to $73.6 \%$ ) $[97,98]$. Two RCTs also reported VE data for study participants who were seronegative and PCR negative for the relevant HPV types at study begin $[97,98]$. Table $3^{*}$ in the online annex shows that VE estimates for all endpoints were higher than those recorded in the analysis, regardless of HPV status at study begin (from $41.1 \%$ against incident anogenital infections with HPV 16 [97] to $100 \%$ against incident and persistent anal infections with HPV 18 [98]). In- 
cident oral infections with HR HPV types were examined in only one study (nonrandomized); it showed VE of $91 \%$ with a broad 95\% CI [89]. The VE against persistent oral HPV infections was $88 \%$ [91] (table $3^{\star}$ in the online annex).

\subsection{Vaccine efficacy/effectiveness against HPV-associated lesions}

Tables $4^{*}$ and $5^{*}$ in the online annex show the VE estimates against HPV-associated anogenital lesions. The VE against genital warts was examined in two RCTs. One RCT reported an estimate of $67.2 \%$, [97] but the other RCT showed no protective effect of the vaccination (VE $=-26 \%$ ) [96]. But the latter RCT included only participants who had already had genital warts in the past, and had a high risk of bias. One RCT and one nonrandomized study reported data on anal genital warts and showed similar study estimates (57.2\% and $55 \%)[98,99]$.

The VE against AIN grade II was $61.9 \%$ in one RCT [98] and 50\% in a non-randomized study [90]. Data on the endpoint AIN grade III was available from only one RCT, showing an insignificant VE of $46.8 \%$ [98]. Data on PIN grade II or III were reported in only one RCT, [97] but no meaningful study estimates could be calculated due to the low number of cases. In a similar fashion, no VE estimates could be calculated for the endpoints anal carcinoma and penile carcinoma because no cases occurred in the studies included $[97,98]$.

Table $5^{\star}$ (see online annex) shows the data on those study participants who were HPV-negative at study begin. In this subgroup the VE estimates for the prevention of anogenital lesions were higher than in the overall group, but the case numbers were so low that no meaningful VE estimate could be reported for AIN, PIN, or corresponding carcinoma.

\subsection{Quality of evidence for efficacy according to GRADE}

For the endpoint Condylomata acuminata, the quality of evidence was found to be "high", but for four other endpoints (incident anogenital infection, persistent oral infection, persistent anogenital in- fection, AIN grade II) it was downgraded to "moderate". The quality of evidence for the endpoint AIN grade III was classified as "low". The quality of evidence for the endpoints incident oral infection and PIN grade II and III was found to be "very low" (see GRADE evidence profile in table $6^{*}$ in the annex).

\subsection{Summary assessment of the efficacy/effectiveness of the HPV vaccination of boys and men}

The data in the systematic review show that HPV vaccination of boys and men has only moderate effectiveness against genital HPV infections and higher grade AIN when it is administered without consideration of the HPV infection status. Higher VE is observed when only those study participants who were not yet infected with HPV were analyzed. These results correspond to those from studies on the HPV vaccination of women, and thus favour vaccination strategies that select HPV-naive persons, i.e. persons who are not yet sexually active, as the primary target group for HPV vaccination. At the same time it must be emphasized that due to the long latency period of the disease, no conclusions can be drawn yet on the effectiveness of the vaccine against higher-grade penile intraepithelial lesions or squamous-cell carcinoma. This underscores the necessity of further studies. Because HPV vaccination of girls is established in many regions of the world in which studies on HPV vaccination effectiveness are ongoing or have been conducted, it will no longer be possible to estimate the actual effectiveness of the HPV vaccination of boys on the population level. This is because herd immunity with positive effects on the HPV-associated disease burden in boys and men has been described (see section 9).

\section{Safety of the HPV vaccination of boys and men}

\subsection{Data from the RKI systematic review}

Severe adverse events were examined in two of the three RCTs included in the systematic review $[97,98]$. None of the nonrandomized studies contain data on the endpoint safety and tolerability of the HPV vaccine. Because the smaller of the two RCTs consisted of a subgroup of participants from a larger RCT, it is assumed that all severe adverse events reported in the smaller RCT were already contained in the larger RCT, so that only the data from the latter were analyzed in the systematic review [97, 98]. A total of 8 events in the vaccinated group (2020 participants) were registered in the observation period, and 11 events occurred in the placebo arm (2029 participants). From this, a relative risk of the occurrence of a severe adverse event after vaccination, compared to placebo, of 0.73 (95\% CI: 0.25-1.99) was calculated; the study authors did not consider any of the events to be caused by the vaccination. The quality of evidence was classified as "moderate".

\subsection{Data from the postmarketing surveillance of the HPV vaccination in girls and women}

Since 2006, more than 270 million HPV vaccine doses have been administered around the world. Since 2007, the WHO Global Advisory Committee on Vaccine Safety (GACVS) has conducted an assessment of the safety data on the HPV vaccine. Evaluations have been conducted in the years 2007, 2008, 2009, 2013, 2014, 2015, and 2017 [100]. Based on the safety data from numerous countries, the only adverse events described after an HPV vaccination have been the risk of anaphylaxis (approx. 1.7 per 1 million vaccine doses) and syncope as a common adverse event as an expression of fear or stress related to the vaccination. In summary, the GAVCS evaluates the HPV vaccines as extremely safe. But it must be noted that the data on the HPV vaccination evaluated was mostly from girls and women.

\subsection{Summary assessment of the safety of the HPV vaccination of boys and men}

The systematic review conducted by the RKI in agreement with the STIKO HPV Working Group showed no severe adverse events following HPV vaccination in boys and men in the market authorization studies. From the data accumulated between 
2006 and 2017 from the postmarketing surveillance of women, it can be concluded that there is no increased risk of severe adverse events after HPV vaccination.

\section{Duration of protection provided by HPV vaccination}

In a systematic review conducted by the RKI in collaboration with the STIKO HPV Working Group in 2014 on the evidence of the duration of protection provided by HPV vaccination against types 16 and 18 in girls and women, no indications of a reduction in vaccine protection were found over time [101]. The data in the systematic reviews refer to 1 or 2 RCTs with a follow-up period of $\geq 5$ years after primary immunization, with the endpoints incident and persistent HPV infection, CIN II+ lesions examined. In accordance with the GRADE methodology, the quality of evidence was classified as "very low". Furthermore, a study showed that the HPV 16 and HPV 18 antibody response after vaccination with the bivalent or tetravalent vaccine is higher for several years than the immune response after a natural infection [102]. In addition, the HPV 16 and HPV 18 antibody response rose again markedly if a booster was administered several years after primary immunization was completed [103]. It can be assumed that HPV vaccination of boys and men will have a duration of protection comparable to that for girls and women.

\section{Effects of vaccinating girls against HPV on HPV epidemiology in boys and men}

Within a few years of routine HPV vaccination for girls being introduced in 2007, indirect effects were observed in unvaccinated women and men in the same age cohort as the vaccinated women. Both the frequency of genital warts caused by LR HPV types 6 and 11 and the anogenital prevalence of HR HPV types covered by the vaccine decreased. The first indications of herd immunity were reviewed in a meta-analysis covering the timeframe 2007 to February 2014 [104].

In recent years, studies on the epidemiology of genital warts have been reported for Australia, the USA, Cana- da, and Europe. The reduction in cases of genital warts is especially pronounced in Australia, which established a schoolbased HPV vaccination program for girls in 2007 and quickly achieved vaccination coverage of over $75 \%$. Within 5 years, a reduction in genital warts of $89.9 \%$ (95\% CI 84.4-93.4\%) among 12- to 17-year-olds, and of $72.7 \%(67.0-77.5 \%)$ among 18 - to 26 -year-olds was achieved. Furthermore, a reduction of $38.3 \%(27.7-47.2 \%)$ was achieved among 18- to 26-year-old men [105]. Indirect, though less pronounced herd immunity effects were also recorded in countries with low HPV vaccination coverage, such as Germany and the USA [106]. In one study in Germany, involving data from four statutory health insurance funds (around 5 million insured persons aged 11-79 years from every region in Germany) were reviewed for diagnoses of genital warts (ICD-10 63.0) in the period 2005-2010. It showed that a significant reduction in genital warts of up to $60 \%$ was achieved in young women aged 16-20 years after only 2 years (since 2009), despite the low vaccination coverage of around $30 \%$ in the first years after the introduction of the HPV vaccination for girls. The incidence rate remained at this low level [107]. From 2009, a significant reduction of $50 \%$ in new cases of genital warts in men aged 16-18 years was also observed. These data showed that even low vaccination coverage in girls can achieve indirect effects on genital warts.

Indirect effects were also described with regard to the anogenital prevalence of HR HPV types in unvaccinated women and men. Corresponding data on men are available from Australia and the USA. In one Australian study from 2005-2007, urine and/or urethral smears from men were examined for HPV, and a significant reduction in HPV prevalence was found. Prior to the introduction of vaccination (2005-2015), the prevalence of HR HPV types 16 and 18 in men born in Australia was $9 \%$ (95\% CI 5-15\%). After the introduction of HPV vaccination for girls (2008-2015), the prevalence was $4 \%$ (3$7 \%)(p=0.049)$, and the prevalence for LR HPV types was 10\% (6-17\%) and 2\% (1$4 \%)(p<0.0001)$ [20]. Another study from Australia showed a $78 \%$ lower prevalence of penile HPV (HPV types 6, 11, 16, and
18) among unvaccinated heterosexual men under 25 years of age than among older men. These data showed that herd immunity effects are detectable with regard to the anogenital prevalence of HR HPV types.

\section{Epidemiological model and health economics analysis of HPV vaccination of boys and men in Germany}

To estimate the epidemiological and economic consequences of introducing vaccination for boys in Germany, a collaboration between the RKI, the STIKO HPV Working Group, the University of Bielefeld, and the Helmholz Centre for Infection Research in Braunschweig developed an epidemiological model and conducted a health economics evaluation based on that. The model structure, assumptions, input parameters, and results of this analysis are summarized below. A detailed project report is provided on the RKI website.

\subsection{Model structure}

The model described here is a refinement of an existing model developed separately by the same working group from Bielefeld $[108,109]$.

The model considers the transmission dynamic of HPV, and is based on a deterministic SIRS approach. In this structure, the model population can be divided into various populations: susceptible (S), infected (I), and resistant (R) persons. It is possible for a person to switch from one group to another, e.g. from susceptible to infected or vice-versa, and some of the infected persons developing a temporary immunity. HPV vaccinated persons were counted in the resistant group.

The epidemiological and health economics impact were examined for the next 100 years from 2017. This time frame was chosen to analyze also long-term effects. Because statements on the population structure in the next 100 years cannot be made with any certainty, modelling was conducted based on an artificial (i. e. stable) population. Each year, one million new people are added through birth, and a defined number of people die each year 
based on mortality rates from the Federal Statistics Office in Germany.

The aim of the model was to examine a scenario that is as realistic as possible. For that reason the effects of the additional HPV vaccination for boys in the presence of existing HPV vaccination for girls were examined. Cytology-based cervical cancer screening was also considered in the model. Because the HPV vaccine was switched from the tetravalent Gardasil ${ }^{\oplus}$ to the nonavalent Gardasil ${ }^{\circ} 9$ in 2017, this switch was also reflected in the model.

\subsection{Assumptions/input data}

As already done for the model structure, major assumptions and input parameters in the initial model are presented in the respective publications [108, 109]. Because the HPV vaccination recommendation for girls was changed in 2014 (vaccination from the age of 9 years and a 2-dose vaccination scheme with the first vaccination before the 15th birthday), both twoand three-dose vaccination schemes were considered in the model. The model included cervical cancer and its precursors, HPV-associated carcinoma of the vulva, vagina, penis, anus, and oropharynx (incidence-based approach), and condylomata acuminata (genital warts). The percentage of HPV-attributable carcinomas (in the base case analysis) is based on the results of the meta-analyses described in

- Table 2. For the base case analysis, it was assumed that $17 \%$ of girls are vaccinated with Cervarix ${ }^{\circledast}$ and $83 \%$ with Gardasil $^{\circ} 9$, and $100 \%$ of boys receive Gardasil ${ }^{\circ}$. VE was determined in systematic reviews, and was higher among women (98-100\%) [100] than among men (79$90 \%$ )(see section 6.3). 20-year protection was assumed; after that, protection wanes gradually ( $10 \%$ per year). The vaccination coverage used in the model is based on data from the Associations of Statutory Health Insurance Physicians (ASHIP) Vaccination Monitoring Project at the RKI for the year 2015 (44.6\% for 17-year-old girls [18]). In order to depict the historical development of vaccination coverage for the single birth cohorts in Germany since 2007 in the model, a linear rise in vaccination coverage from the age of 9 years (since 2015) and 12 years of age (from
2007 to 2014), respectively, until reaching the cumulative vaccination coverage of $44.6 \%$ was assumed. Furthermore, it was assumed that vaccination coverage of $22.3 \%$ of 17 -year-old boys is achieved, half the coverage of girls (44.6\%).

The health economics evaluation was conducted using a cost-benefit analysis, i. e. the costs of each additional QALY (quality-adjusted life year) were defined. Costs to statutory health insurance (SHI) alone (SHI perspective) and overall costs to society (societal perspective) were analyzed. A discount rate of $3 \%$ was applied to future costs and health effects. Direct costs such as vaccine price or treatment costs of HPV-associated diseases, as well as indirect costs (e.g. loss of production costs due to work absenteeism), were used as basis.

The analysis of the epidemiological and health economics impact of HPV vaccination for boys was conducted incrementally, i.e. the comparison is always to the scenario of existing HPV vaccination for girls.

The assumptions of the base case analysis were varied individually in sensitivity analyses (e.g. higher vaccination coverage for both genders or better VE for boys and men).

\subsection{Results of the epidemiological model}

Using the assumptions of the base case analysis-as described under 10.2-an additional 22,122 cases of cervical cancer and 25,226 cases of other HPV-associated carcinomas (in men and women) could be prevented in the next 100 years if $22.3 \%$ of boys are vaccinated against HPV in addition to girls (vaccination coverage of 44.6\%). Furthermore, an additional 5834 deaths from cervical cancer and 10,279 deaths from other HPV-associated carcinomas could be prevented through HPV vaccination of boys. The number of preventable cancer cases and deaths would rise if the vaccination coverage of boys is higher, i. e. greater than $22.3 \%$ at the age of 17 years, or if the same VE against infections is assumed for men as for women. The numbers needed to vaccinate (NNV) were estimated using the base case analysis. 527 boys would need to be vaccinated against HPV to prevent one case of cervi- cal cancer (NNV: 527). The NNV to prevent one $\mathrm{HPV}$-associated case of cancer (in women and men) is 246 , and 724 are needed to prevent one death caused by HPV-associated carcinoma-both numbers refer to the HPV vaccination of boys. To prevent one case of genital warts (in women and men) 64 boys would need to be vaccinated.

\subsection{Results of the health economics analysis}

Two perspectives were considered in the assessment of health economics outcomes of HPV vaccination for boys: the perspective of the statutory health insurance funds, which is informed by the direct health and disease costs (i.e. vaccination costs and treatment costs in the case of disease), and the societal perspective, which takes into account additional indirect costs such as absenteeism from work. Using the assumptions from the base case analysis, with a presumed vaccine price of $€ 113.40$ per dose for Cervarix ${ }^{\oplus}$ and $€ 138.27$ for Gardasil ${ }^{\circledR} 9$, statutory health insurance funds would need to spend $€ 29,913$ per QALY, and the cost to society per QALY would be $€ 26,177$. That means that the incremental cost-effectiveness ratios (ICERs), defined as costs per QALY in $€$, are around $€ 30,000$ and $€ 26,000$, respectively. Sensitivity analyses showed that the HPV vaccine price, the change in the discount rate, and the vaccination coverage among girls are the factors with the strongest impact on the results of the health economics analysis. Cutting the vaccine price by $50 \%$ would result in an ICER clearly below $€ 10,000$. The herd immunity effects become more pronounced as the HPV vaccination coverage of girls rises. The ICER rises considerably with high vaccination coverage of girls, achieving levels of over $€ 200,000$ per QALY at a girls vaccination coverage of $80 \%$.

It must be noted that the epidemiological and health economics consequences of premature births due to HPV-associated conization were not taken into account in this model $[110,111]$. 


\subsection{Conclusion}

The dynamic transmission model shows that in the base case analysis, HPV vaccination of boys leads to a marked reduction in the disease burden of HPV-associated tumours in both genders. If HPV vaccination coverage of girls rises to over $60 \%$, the epidemiological effects of HPV vaccination for boys are reduced significantly. The health economics analysis shows that besides vaccination coverage, the vaccine price in particular has a strong impact on the cost-benefit ratio of the additional HPV vaccination for boys.

\section{Implementation and feasibility of HPV vaccination for boys}

\subsection{Dosage and type of administration}

According to the product information, Cervarix $^{\circledast}$ is administered at the age of 9-14 years in a two-dose scheme. The second vaccine dose can be administered 5-13 months after the first dose. If the second dose is administered less than 5 months after the first dose, a third dose must be administered. If primary immunization is performed at the age of 15 years or older-i. e. if the first vaccine dose is administered at the age of 15 years or older-Cervarix ${ }^{\oplus}$ is administered using a three-dose scheme in months 0-1-6. Intramuscular injection is administered via the m. deltoideus; no data are available on subcutaneous administration. If Cervar$\mathrm{ix}^{\infty}$ is administered simultaneously with another injectable vaccine, one should always be administered in the right and the other in the left $\mathrm{m}$. deltoideus.

According to the product information, Gardasil ${ }^{\circ} 9$ is administered at the age of 9-14 years in a two-dose scheme. The second vaccine dose can be administered 5-13 months after the first dose. If the second dose is administered less than 5 months after the first dose, a third dose must be administered. If primary immunization is performed at the age of 15 years or older-i. e. if the first vaccine dose is administered at the age of 15 years or olderGardasil ${ }^{\oplus} 9$ is administered using a threedose scheme in months $0-2-6$. The second dose should be administered one month after the first one at the earliest, and the third dose three months after the second dose at the earliest. All three doses should be administered within a timeframe of 1 year. Gardasil ${ }^{\circledR} 9$ must be administered as an intramuscular injection, preferable in the m. deltoideus.

\subsection{Coadministration with other vaccines}

According to the product information, Cervarix $^{\circledast}$ can be administered simultaneously with a combination booster against diphtheria (d), tetanus $(\mathrm{T})$, and pertussis (acellular $=a p$ ), with or without the inactivated poliomyelitis (IPV) (Tdpa, Tdpa-IPV vaccines) without causing clinically relevant impairments in the antibody response to one of the components contained in the two vaccines. Cervarix ${ }^{\circledast}$ can also be administered simultaneously with a combined hepatitis A (inactivated) and hepatitis B (rDNA) vaccine (Twinrix ${ }^{\circledR}$ ), or simultaneously with a hepatitis B (rDNA) vaccine (Engerix- $B^{\circledast}$ ).

According to the product information, Gardasil ${ }^{\circ} 9$ can be administered simultaneously with a booster dose against diphtheria (d) and tetanus ( $\mathrm{T})$, combined with either pertussis [acellular, from components] (ap) and/or poliomyelitis [inactivated] (IPV) (Tdap, Td-IPV, Tdap-IPV vaccines).

\subsection{Contraindications}

According to the product information, Cervarix $^{\oplus}$ and Gardasil ${ }^{\oplus} 9$ should not be used in the presence of hypersensitivity to one of the active ingredients contained in the vaccine or to excipients named in the product information. In addition, persons exhibiting hypersensitivity after a previous administration of Gardasil ${ }^{\oplus} 9$ or Gardasil ${ }^{\oplus}$ / Silgard ${ }^{\circledR}$ should not receive any more doses of Gardasil ${ }^{\circledR}$ 9. In the case of pregnancy, HPV vaccination should be delayed.

\section{Acceptance of the HPV vaccination for boys and aspects of equal treatment of the genders}

\subsection{Acceptance}

The vaccination coverage of $45 \%$ (full vaccination series in 17-year-old girls, 2015) [18] signals that the routine vaccination of girls against HPV is not well accepted in Germany. In a Facebook survey of young women aged 18-25 years living in Germany, unvaccinated women named safety concerns and the fear of side effects as the most frequent reasons for not being vaccinated [112]. The most important factor in the decision to have the vaccination was recommendation by a physician. The importance of a physician's recommendation was also evident in two surveys by the Federal Centre for Health Education (BZgA $[113,114])$, as well as in other studies from countries without a school vaccination programme for HPV $[115,116]$. A study from Canada proved that acceptance of the HPV vaccination increases when it is offered to both genders [117].

To achieve high acceptance of the HPV vaccination for boys (and girls), safety concerns regarding HPV vaccination should be addressed in the respective target groups, including parents, and physicians should be reminded to actively offer the vaccination to the relevant age groups.

\subsection{Gender equity}

Following the principle of gender equity, vaccinating boys and men against HPV allows them to build up their own immunity to HPV infection or to possible sequelae such as genital warts and carcinoma, regardless of the vaccination coverage of girls. Furthermore, vaccinating both genders against HPV distributes the responsibility for reducing the HPV disease burden in Germany to both genders equally. In addition, it must be considered that MSM, a population with a markedly increased risk of HPV infection, do not benefit (or benefit only slightly) from the herd immunity induced by vaccinating girls because their sexual contact occurs exclusively or nearly exclusively among men. Vaccinating boys against HPV then 
allows MSM to develop immunity to HPV before becoming sexually active.

\subsection{Implementation of a general HPV vaccination}

Like girls, boys should be vaccinated against HPV between the ages of 9 and 14 years. The aim is to complete the HPV vaccination series before the first sexual contact, if possible. A catch-up vaccination should be administered by or at the age of 17 years. Whenever possible, the HPV vaccination should be offered to unvaccinated or not fully vaccinated boys at each physician's visit. In particular, the routine adolescent health check-up ' 11 ' (offered to 12-14-year-olds) is an opportunity for HPV vaccination. An analysis of ASHIP data has shown that 12-year-old girls have a 7 times higher probability of having received at least one HPV vaccine dose if they attended the J1 health checkup [118]. The introduction of a compulsory invitation and response procedure for the J1 health check-up could be helpful: in the Rhineland-Palatinate, this procedure has increased attendance at the J1 health check-up by $25 \%$ [119]. The routine well-child check-up 'U11' (9-10 years of age) is another option for offering the vaccination, but not all SHI funds cover this screening examination, so it is not offered consistently in Germany.

To achieve high HPV vaccination coverage, a nationwide school-based vaccination programme should be considered for Germany to reach those children who have not visited a doctor between the ages of 9 and 14 years, who have not attended the J1 health check-up, or whose doctors have not yet recommended HPV vaccination. School vaccination programmes are most common in Anglo-Saxon and Nordic countries, where they normally lead to a vaccination coverage of $>70 \%$, as in Australia (2016: girls $79 \%$, boys 73\%; [120]), Canada (2013: girls 73\%; [121]), the UK (2015/16: girls 85.3\%; [122]), Norway (2017: girls 83\%; [123]), and Sweden (2016: girls 73-77\%; [124]). By contrast, in countries with no school vaccination programme, lower vaccination coverage has been observed so far, e.g. in the USA (2016: girls 50\%, boys $38 \%$; [125]), Switzerland (2011-13: girls 51\%; [126]), and France (2010: girls 55\%; [127]). One exception is Denmark, which initially achieved vaccination coverage of $>70 \%$ after introduction of the vaccination without a school vaccination programme [128]. In a Canadian study of 35,000 girls in school grades 5-9, HPV vaccination was offered in Ontario either as a school vaccination, or the girls needed to visit a public health clinic in their communities [129]. The vaccination coverage for complete HPV vaccination was $75 \%$ (95\% CI 74.7\%-75.8\%) for girls who had received the HPV vaccination in school, and 36\% (95\% CI 35.3\%$37.2 \%)$ for girls who were vaccinated in a public health clinic. In other words, vaccination coverage was significantly higher if the girls were vaccinated against HPV in a school vaccination programme. In addition, significantly lower vaccination coverage was observed among girls from families with a low socioeconomic status when vaccination was offered in a public health clinic than among girls with a low socioeconomic status who were offered vaccination in school. These findings indicate that in addition to achieving higher vaccination coverage, school vaccination programmes can also counteract inequalities in access to medical care for population groups with a low socioeconomic status.

These results on the potential of the J1 health check-up and the high vaccination coverage in countries with school-based vaccination programmes indicate that structural changes are necessary in Germany to achieve broad vaccination coverage of $70 \%$ or more among girls and boys.

\subsection{Physician support in the practical implementation of the HPV vaccination recommendation}

Two BZgA surveys on vaccination behaviour patterns from 2011 [113] and 2014 [114] have shown that the physician plays a key role in the implementation of vaccination recommendations in Germany. The important role of doctors as the main source of information for or against HPV vaccination was also seen in the Facebook survey of young girls on HPV vaccination mentioned above [112]. Studies from the USA, where HPV vaccination is also giv- en by physicians in private practices and vaccination coverage is comparable to that in Germany, have identified various communication measures that prove promising in terms of doctors' consultation on HPV vaccination. These include the use of information graphics showing the benefit of HPV vaccination [130], communicating risks using comparisons from everyday life [131], and other specific communication strategies. Public Health England has also had good results by providing factsheets on each vaccination. It would therefore be desirable to support the introduction of HPV vaccination for boys with relevant educational material for doctors, e.g. an HPV factsheet developed by the RKI for doctors and a factsheet with graphics which can serve as the basis for the doctor's vaccination advice to parents, children, and adolescents.

Furthermore, the survey of parents in the BZgA study from 2013 showed that $63 \%$ used information brochures and leaflets as a source of information on vaccination [114]. BZgA materials for parents and children/adolescents as an accompaniment to HPV vaccination recommendations, as well as a possible vaccination campaign for both genders, would be sensible measures to support the RKI educational package for doctors.

\subsection{Evaluation of the vaccination recommendation}

The ASHIP Vaccination Monitoring Project is the only tool for assessing the nationwide vaccination coverage at any time other than the start-of-school examination in Germany [118]. This surveillance can assess vaccination coverage among persons insured under statutory health insurance, who constitute around $85 \%$ of the overall population in Germany. The nationwide German Health Interview and Examination Survey for Children and Adolescents (Studie zur Gesundheit von Kindern und Jugendlichen in Deutschland, KiGGS), which is both a cross-sectional and longitudinal study, as well as RKI Health Monitoring of the adult population in Germany, can also be used in the future to describe the link between uptake of the HPV vaccination and other factors, such as socioeconomic status, migration 


\begin{tabular}{|c|c|}
\hline \multicolumn{2}{|c|}{ Abbreviations } \\
\hline AIN & Anal intraepithelial neoplasia \\
\hline ASHIP & Association of Statutory Health Insurance Physicians (Kassenärztliche Vereinigung) \\
\hline AWMF & $\begin{array}{l}\text { The Association of the Scientific Medical Societies (Arbeitsgemeinschaft der } \\
\text { Wissenschaftlichen Medizinischen Fachgesellschaften) }\end{array}$ \\
\hline$B Z g A$ & Federal Centre for Health Education (Bundeszentrale für gesundheitliche Aufklärung) \\
\hline $\mathrm{Cl}$ & Confidence interval \\
\hline CIN & Cervical intraepithelial neoplasia \\
\hline DNA & Deoxyribonucleic acid \\
\hline GACVS & Global Advisory Committee on Vaccine Safety \\
\hline GRADE & Grading of recommendations assessment, development and evaluation \\
\hline$H I V$ & Human immunodeficiency virus \\
\hline HPV & Human papillomavirus \\
\hline$H R$ & High-risk \\
\hline IARC & International Agency for Research on Cancer \\
\hline$I C D-10$ & International Classification of Diseases, 10th revision \\
\hline ICER & Incremental cost-effectiveness ratio \\
\hline$L R$ & Low-risk \\
\hline MSM & Men who have sex with men \\
\hline NNV & Number needed to vaccinate \\
\hline$P C R$ & Polymerase chain reaction \\
\hline PEI & Paul Ehrlich Institute \\
\hline PIN & Penile intraepithelial neoplasia \\
\hline PROSPERO & Prospective register for systematic reviews \\
\hline PY & Person-years \\
\hline QALY & Quality-adjusted life year \\
\hline$R C T$ & Randomized controlled trial \\
\hline RKI & Robert Koch Institute \\
\hline$R R$ & Relative risk \\
\hline SEER & Surveillance, Epidemiology, and End Results Program \\
\hline SHI & Statutory health insurance \\
\hline SIRS & Susceptible-infected_resistant_-susceptible \\
\hline SOP & Standard operating procedure \\
\hline STI & Sexually transmitted diseases \\
\hline STIKO & Standing Committee on Vaccination \\
\hline TNM & Primary Tumour $(\mathrm{T})$ —regional lymph nodes $(\mathrm{N})$ - distant metastasis $(\mathrm{M})$ \\
\hline$V E$ & Vaccination efficacy/effectiveness \\
\hline WHO & World Health Organization \\
\hline ZfKD & German Centre for Cancer Registry Data (Zentrum für Krebsregisterdaten) \\
\hline $5 Y S R$ & 5-year survival rate \\
\hline
\end{tabular}

background, or visits to a specialist physician [132].

There is no notification requirement for HPV infection in Germany. To evaluate the HPV vaccination recommendation and its effects at the population dermatology, urology, and ENT practices, as well as special-focus practices, pathology laboratories, cytology laboratories, and if applicable clinics from various disciplines involved with the diagnosis and treatment.

Data on vaccine safety after the introduction of a routine HPV vaccination for boys will be recorded using the passive surveillance system of the Paul Ehrlich Institute (PEI). No intensified surveillance of adverse effects is currently planned after the HPV vaccination recommendation for girls in 2007. It should be considered whether the data from the ASHIP Vaccination Monitoring Project can be used to conduct a further analysis of possible adverse events, but the validity of possible analyses based on the structure of the ASHIP data should first be examined in greater detail.

\section{Final assessment}

Because HPV infections in the sexually active population are frequent, HPV-attributable carcinoma presents a relevant disease burden if HPV vaccinations are not administered. Based on cross-sectional studies and meta-analyses, around 1600-2300 cases of HPV-attributable anal, penile, and oropharyngeal carcinoma occur in men each year in Germany. This is in addition to frequent HPV-attributable genital warts. The data in the systematic review indicate that the HPV vaccination of boys and men is highly effective against genital HPV infections and higher-grade AIN if the study participants have not yet been infected with HPV at the time of vaccination. These findings favour a vaccination strategy aimed at HPV-naive persons who are not yet sexually active. The systematic review also showed no severe adverse events after the HPV vaccination of boys and men in the market authorization studies. From the data accumulated between 2006 and 2017 from the postmarketing surveillance of women, it can also be concluded that there is no increased risk of severe adverse events after HPV vaccination. If the current HPV vaccination coverage of girls is applied to the model of HPV vaccination for boys, it shows that the HPV vaccination of boys leads 
to a marked reduction in the disease burden of HPV-associated tumours in both genders. This could prevent an additional 22,122 cases of cervical carcinoma and 25,226 of other HPV-associated carcinoma (in girls and women) over the next 100 years. The NNV to prevent one case of HPV-associated cancer (in women and men) is 246 boys. Following the principle of gender equity, vaccinating boys and men against HPV allows them to build up their own immunity to HPV infection or genital warts and carcinoma, regardless of the vaccination coverage of girls. Furthermore, it distributes the responsibility for reducing the HPV disease burden in Germany to both genders equally. Finally, vaccinating MSM, a population with a markedly higher risk of HPV infection, against HPV as boys allows them to build up protection from HPV before they become sexually active.

\section{Acknowledgements. We thank Heiko Jessen (Berlin, Germany), Jens Peter Klußmann (Cologne, Germany), Oliver Damm (Bielefeld, Germany), Klaus Kraywinkel (Berlin, Germany) und Nina Butt- mann-Schweiger (Berlin, Germany) for comments. We thank William Chaney (www.english-in- form.com) for translation and Kate Fox, DPhil, from Edanz Group (www.edanzediting.com/ac) for editing a draft of this manuscript.}

S. J. Klug received an authorship honorarium from Georg Thieme Publishers, reimbursement of travel costs from the German Society of Urology, and a speakers honorarium from RG Gesellschaft für Information und Organisation. M. Röbl-Mathieu received a speakers honorarium from the Frauenärztliche Bundesakademie. F. Zepp received a speakers honorarium from med-update. All other authors declare that they have no conflicts of interest.

Stefanie J. Klug, Jörg J. Meerpohl, Marianne Röbl-Mathieu, Martin Terhardt, Marianne van der Sande and Fred Zepp are members of the German Standing Committee on Vaccination (STIKO).

\section{References}

1. AG HPV der Ständigen Impfkommission (STIKO) (2018) Wissenschaftliche Begründung für die Empfehlung der HPV-Impfung für Jungen im Alter von 9 bis 14 Jahren. Epid Bull(26):233-250. https://doi.org/10.17886/EpiBull-2018-032

2. Catalan Institute of Oncology (ICO) International Agency for Research on Cancer (IARC): HPV Information Centre 2018. www.hpvcentre.net. Accessed 27 Nov 2017

3. Schiffman M, Castle PE, Jeronimo J et al (2007) Human papillomavirus and cervical cancer. Lan- cet 370(9590):890-907. https://doi.org/10.1016/ S0140-6736(07)61416-0

4. Bodily J, Laimins LA (2011) Persistence of human papillomavirus infection: keys to malignant progression. Trends Microbiol 19(1):33-39. https:// doi.org/10.1016/j.tim.2010.10.002

5. Herrero R, Castellsague $X$, Pawlita $M$ et al (2003) Human papillomavirus and oral cancer: the International Agency for Research on Cancer multicenter study. J Natl Cancer Inst 95(23):1772-1783

6. McCredie MR, Sharples KJ, Paul C et al (2008) Natural history of cervical neoplasia and risk of invasive cancer in women with cervical intraepithelial neoplasia 3: a retrospective cohort study. Lancet Oncol 9(5):425-4234. https:// doi.org/10.1016/S1470-2045(08)70103-7

7. Franco EL, Villa LL, Sobrinho JP et al (1999) Epidemiology of acquisition and clearance of cervical human papillomavirus infection in women from a high-risk area for cervical cancer. J Infect Dis 180(5):1415-1423. https:// doi.org/10.1086/315086

8. Woodman CB, Collins S, Winter H et al (2001) Natural history of cervical human papillomavirus infection in young women: a longitudinal cohort study. Lancet 357(9271):1831-1836. https:// doi.org/10.1016/S0140-6736(00)04956-4

9. Munoz N, Mendez F, Posso H et al (2004) Incidence, duration, and determinants of cervical human papillomavirus infection in a cohort of Colombian women with normal cytological results. J Infect Dis 190(12):2077-2087. https:// doi.org/10.1086/425907

10. Walboomers JM, Jacobs MV, Manos MM et al (1999) Human papillomavirus is a necessary cause of invasive cervical cancer worldwide. J Pathol 189(1):12-19. https://doi.org/10.1002/ (SICI)1096-9896(199909)189

11. Zentrum für Krebsregisterdaten, Gesellschaft der epidemiologischen Krebsregister in Deutschland e. V., editors: Krebs in Deutschland für 2013/2014. 11. Ausgabe ed. Berlin: Robert Koch-Institut 2017

12. de Sanjose S, Alemany L, Ordi J et al (2013) Worldwide human papillomavirus genotype attribution in over 2000 cases of intraepithelial and invasive lesions of the vulva. Eur J Cancer 49(16):3450-3461. https://doi.org/10.1016/j. ejca.2013.06.033

13. Alemany L, Saunier M, Tinoco L et al (2014) Large contribution of human papillomavirus in vaginal neoplastic lesions: a worldwide study in 597 samples. Eur J Cancer 50(16):2846-2854. https:// doi.org/10.1016/j.ejca.2014.07.018

14. Alemany L, Saunier M, Alvarado-Cabrero I et al (2015) Human papillomavirus DNA prevalence and type distribution in anal carcinomas worldwide. Int J Cancer 136(1):98-107. https:// doi.org/10.1002/ijc.28963

15. Castellsague X, Alemany L, Quer M et al (2016) HPV Involvement in Head and Neck Cancers: Comprehensive Assessment of Biomarkers in 3680 Patients. J Natl Cancer Inst 108(6):djv403. https://doi.org/10.1093/jnci/djv403

16. Robert Koch-Institut (2007) Mitteilung der Ständigen Impfkommission (STIKO) am Robert Koch-Institut: Impfung gegen humane Papillomaviren (HPV) für Mädchen von 12 bis 17 Jahren - Empfehlung und Begründung. Epid Bull 12:97-103

17. Robert Koch-Institut (2017) Aktuelles aus der KV-Impfsurveillance: Impfquoten der
Rotavirus-, Masern-, HPV- und Influenza-Impfung in Deutschland. Epid Bull 1:1-12. https:// doi.org/10.17886/EpiBull-2017-001

18. Rieck T, Feig M, Siedler A et al (2018) Aktuelles aus der KV-Impfsurveillance. Impfquoten Ausgewählter Schutzimpfungen Deutschland Epid Bull 1:1-14. https://doi.org/10.17886/ EpiBull-2018-001.3

19. Zentrum für Krebsregisterdaten Datenbankabfrage: Robert Koch-Institut; 2017. www. krebsdaten.de/Krebs/DE/Home/homepage_ node.html. Accessed 11 Sept 2017

20. Chow EPF, Machalek DA, Tabrizi SN et al (2017) Quadrivalent vaccine-targeted human papillomavirus genotypes in heterosexual men after the Australian female human papillomavirus vaccination programme: a retrospective observational study. Lancet Infect Dis 17(1):68-677. https://doi.org/10.1016/S1473-3099(16)30116-5

21. Manhart LE, Koutsky LA (2002) Do condoms prevent genital HPV infection, external genital warts, or cervical neoplasia? A meta-analysis. Sex Transm Dis 29(11):725-735

22. Nielson CM, Harris RB, Nyitray AG et al (2010) Consistent condom use is associated with lower prevalence of human papillomavirus infection in men. J Infect Dis 202(3):445-451. https:// doi.org/10.1086/653708

23. Hebner CM, Laimins LA (2006) Human papillomaviruses: basic mechanisms of pathogenesis and oncogenicity. Rev Med Virol 16(2):83-97. https://doi.org/10.1002/rmv.488

24. Doorbar J, Quint W, Banks L et al (2012) The biology and life-cycle of human papillomaviruses. Vaccine 30(Suppl 5):F55-70. https:// doi.org/10.1016/j.vaccine.2012.06.083

25. Viarisio D, Gissmann L, Tommasino M (2017) Human papillomaviruses and carcinogenesis: well-established and novel models. Curr Opin Virol 26(5):62. https://doi.org/10.1016/j.coviro.2017.07.014

26. Bussu F, Sali M, Gallus R et al (2013) HPV infection in squamous cell carcinomas arising from different mucosal sites of the head and neck region. Is p16 immunohistochemistry a reliable surrogate marker? Br J Cancer 108(5):11571162. https://doi.org/10.1038/bjc.2013.55

27. WHO-IARC IARC Monographs: List of classifications by cancer site 2017. http://monographs. iarc.fr/ENG/Classification/Table4.pdf. Accessed 23 Jan 2018

28. Moscicki AB, Schiffman $M$, Burchell $A$ et al (2012) Updating the natural history of human papillomavirus and anogenital cancers. Vaccine 30(5):F24-33. https://doi.org/10.1016/j.vaccine.2012.05.089

29. Steben M, Garland SM (2014) Genital warts. Best Pract Res Clin Obstet Gynaecol 28(7):1063-1073. https://doi.org/10.1016/j.bpobgyn.2014.07.002

30. Gross GE, Werner RN, Becker JC, et al.: S2k Leitlinie „HPV-assoziierte Läsionen der äußeren Genitalregion und des Anus - Genitalwarzen und Krebsvorstufen der Vulva, des Penis und der peri- und intraanalen Haut". AWMF 2018;AWMF-Registernummer: 082 - 008(www.awmf.org)

31. Hakenberg OW, Minhas S, Necchi A et al (2016) Oncology Guidelines: Penile Cancer. European Association of Urology. http://uroweb.org/ guideline/penile-cancer/. Accessed: 27 Nov 2017

32. Chaux A, Netto GJ, Rodriguez IM et al (2013) Epidemiologic profile, sexual history, pathologic features, and human papillomavirus status of 103 patients with penile carcinoma. World J Urol 
31(4):861-867. https://doi.org/10.1007/s00345011-0802-0

33. Larke NL, Thomas SL (2011) dos Santos Silva I, et al.: Male circumcision and penile cancer: a systematic review and meta-analysis. Cancer Causes Control 22(8):1097-1110. https:// doi.org/10.1007/s10552-011-9785-9

34. Deen K, Burdon-Jones D (2017) Imiquimod in the treatment of penile intraepithelial neoplasia: An update. Australas J Dermatol 58(2):86-92. https://doi.org/10.1111/ajd.12466

35. Wittekind C, Meyer HJ (2013) TNM: Klassifikation Maligner Tumoren, 7th edn. Wiley-VCH Verlag $\mathrm{GmbH} \&$ Co KGaA, Weinheim

36. Fenger C, Frisch M, Marti MC et al (2000) Tumours of the anal canal. In: Hamilton SR, Aaltonen LA (eds) Pathology and Genetics of Tumours of the Digestive System. WHO Classification of Tumours, vol 2. IARC Press, Lyon, pp 145-155

37. Saraiya $M$, Unger ER, Thompson TD et al (2015) US assessment of HPV types in cancers: implications for current and 9-valent HPV vaccines. J Natl Cancer Inst 107(6):djv86. https:// doi.org/10.1093/jnci/djv086

38. Hensel M, Goetzenich A, Lutz T et al (2011) HIV and Cancer in Germany. Dtsch Arztebl Int 108(8):117-122

39. Raptis D, Schneider I, Matzel KE et al (2015) The differential diagnosis and interdisciplinary treatment of anal carcinoma. Dtsch Arztebl Int 112(14):243-249

40. WHO-IARC IARC Monographs on Biological Agents Volume 100B: A Review of Human Carcinogens 2012. http://monographs.iarc.fr/ENG/ Monographs/vol100B/mono100B.pdf. Accessed 27 Jan 2016

41. Gillison ML, D'Souza G, Westra W et al (2008) Distinct risk factor profiles for human papillomavirus type 16-positive and human papillomavirus type 16-negative head and neck cancers. J Natl Cancer Inst 100(6):407-420. https:// doi.org/10.1093/jnci/djn025

42. Wittekind C (ed) (2017) TNM Klassifikation maligner Tumoren, 8th edn. Wiley-VCH, Weinheim

43. Wolff KD, Bootz F, Beck J, et al.: Mundhöhlenkarzinom Diagnostik und Therapie des Mundhöhlenkarzinoms. AWMF Leitlinie 2012;007 - 100 OL(2)

44. Gillison ML, Alemany L, Snijders PJ et al (2012) Human papillomavirus and diseases of the upper airway: head and neck cancer and respiratory papillomatosis. Vaccine 30(5):F34-54. https://doi.org/10.1016/j.vaccine.2012.05.070

45. Mallen-St Clair J, Alani M, Wang MB et al (2016) Human papillomavirus in oropharyngeal cancer: The changing face of a disease. Biochim Biophys Acta 1866(2):141-150. https://doi.org/10.1016/j. bbcan.2016.07.005

46. O'Rorke MA, Ellison MV, Murray LJ et al (2012) Human papillomavirus related head and neck cancer survival: a systematic review and meta-analysis. Oral Oncol 48(12):1191-1201. https://doi.org/10.1016/j.oraloncology.2012.06.019

47. Ang KK, Harris J, Wheeler R et al (2010) Human papillomavirus and survival of patients with oropharyngeal cancer. N Engl J Med 363(1):24-35. https://doi.org/10.1056/NEJMoa0912217

48. de Martel C, Ferlay J, Franceschi S et al (2012) Global burden of cancers attributable to infections in 2008: a review and synthetic analysis. Lancet Oncol 13(6):607-615. https:// doi.org/10.1016/S1470-2045(12)70137-7
49. O'Sullivan B, Huang SH, Siu LL et al (2013) Deintensification candidate subgroups in human papillomavirus-related oropharyngeal cancer according to minimal risk of distant metastasis. J Clin Oncol 31(5):543-550. https:// doi.org/10.1200/JCO.2012.44.0164

50. Spence T, Bruce J, Yip KW et al (2016) HPV Associated Head and Neck Cancer. Cancers (Basel) 8(8). https://doi.org/10.3390/cancers8080075

51. Ndiaye C, Mena M, Alemany L et al (2014) HPV DNA, E6/E7 mRNA, and p16INK4a detection in head and neck cancers: a systematic review and meta-analysis. Lancet Oncol 15(12):1319-1331. https://doi.org/10.1016/S1470-2045(14)70471-1

52. De Vuyst $\mathrm{H}$, Clifford GM, Nascimento $M C$ et al (2009) Prevalence and type distribution of human papillomavirus in carcinoma and intraepithelial neoplasia of the vulva, vagina and anus: a meta-analysis. Int J Cancer 124(7):1626-1636. https://doi.org/10.1002/ijc.24116

53. Miralles-Guri C, Bruni L, Cubilla AL et al (2009) Human papillomavirus prevalence and type distribution in penile carcinoma. J Clin Pathol 62(10):870-878. https://doi.org/10.1136/ jcp.2008.063149

54. Alemany L, Cubilla A, Halec G et al (2016) Role of Human Papillomavirus in Penile Carcinomas Worldwide. Eur Urol 69(5):953-961. https:// doi.org/10.1016/j.eururo.2015.12.007

55. Anantharaman D, Abedi-Ardekani B, Beachler DC et al (2017) Geographic heterogeneity in the prevalence of human papillomavirus in head and neck cancer. Int J Cancer 140(9):1968-1975. https://doi.org/10.1002/ijc.30608

56. Abogunrin S, Di Tanna GL, Keeping S et al (2014) Prevalence of human papillomavirus in head and neck cancers in European populations: a meta-analysis. BMC Cancer 14:968. https:// doi.org/10.1186/1471-2407-14-968

57. Dunne EF, Nielson CM, Stone KM et al (2006) Prevalence of HPV infection among men: A systematic review of the literature. J Infect Dis 194(8):1044-1057. https:// doi.org/10.1086/507432

58. Gargano JW, Unger ER, Liu G et al (2017) Prevalence of Genital Human Papillomavirus in Males, United States, 2013 - 2014. J Infect Dis 215(7):1070-1079. https://doi.org/10.1093/ infdis/jix057

59. Kjaer SK, Breugelmans G, Munk C et al (2008) Population-based prevalence, type- and age-specific distribution of HPV in women before introduction of an HPV-vaccination program in Denmark. Int J Cancer 123(8):1864-1870. https://doi.org/10.1002/ijc.23712

60. Taylor S, Bunge E, Bakker M et al (2016) The incidence, clearance and persistence of non-cervical human papillomavirus infections: a systematic review of the literature. Bmc Infect Dis 16:293. https://doi.org/10.1186/s12879-016-1633-9

61. Giuliano AR, Lazcano-Ponce E, Villa LL et al (2008) The human papillomavirus infection in men study: human papillomavirus prevalence and type distribution among men residing in Brazil, Mexico, and the United States. Cancer Epidemiol Biomarkers Prev 17(8):2036-2043. https://doi.org/10.1158/1055-9965.EPI-08-0151

62. van Aar F, Mooij SH, van der Sande MA et al (2013) Anal and penile high-risk human papillomavirus prevalence in HIV-negative and HIV-infected MSM. AIDS 27(18):2921-2931. https:// doi.org/10.1097/01.aids.0000432541.67409.3c
63. Goldstone S, Palefsky JM, Giuliano AR et al (2011) Prevalence of and risk factors for human papillomavirus (HPV) infection among HIV-seronegative men who have sex with men. J Infect Dis 203(1):66-74. https://doi.org/10.1093/infdis/ jiq016

64. Wieland U, Hellmich M, Wetendorf J et al (2015) Smoking and anal high-risk human papillomavirus DNA loads in HIV-positive men who have sex with men. Int J Med Microbiol 305(7):689-696. https://doi.org/10.1016/j.ijmm.2015.08.019

65. Nagata N, Watanabe K, Nishijima T et al (2015) Prevalence of Anal Human Papillomavirus Infection and Risk Factors among HIV-positive Patients in Tokyo, Japan. PLoS ONE 10(9):e137434. https://doi.org/10.1371/journal.pone.0137434

66. Denny LA, Franceschi S, de Sanjose $S$ et al (2012) Human papillomavirus, human immunodeficiency virus and immunosuppression. Vaccine 30(Suppl 5):F168-74. https://doi.org/10.1016/j. vaccine.2012.06.045

67. Kreimer AR, Bhatia RK, Messeguer AL et al (2010) Oral human papillomavirus in healthy individuals: a systematic review of the literature. Sex Transm Dis 37(6):386-391. https:// doi.org/10.1097/OLQ.0b013e3181c94a3b

68. Rollo F, Latini A, Pichi B et al (2017) Prevalence and determinants of oral infection by Human Papillomavirus in HIV-infected and uninfected men who have sex with men. PLoS ONE 12(9):e184623. https://doi.org/10.1371/journal. pone. 0184623

69. Daubisse-Marliac L, Colonna M, Tretarre B et al (2017) Long-term trends in incidence and survival of penile cancer in France. Cancer Epidemiol:125-131. https://doi.org/10.1016/j. canep.2017.08.014

70. Trama A, Foschi R, Larranaga N et al (2015) Survival of male genital cancers (prostate, testis and penis) in Europe 1999 - 2007: Results from the EUROCARE-5 study. Eur J Cancer 51(15):22062216. https://doi.org/10.1016/j.ejca.2015.07.027

71. Diorio GJ, Giuliano AR (2016) The Role of Human Papilloma Virus in Penile Carcinogenesis and Preneoplastic Lesions: A Potential Target for Vaccination and Treatment Strategies. Urol Clin North Am 43(4):419-425. https:// doi.org/10.1016/j.ucl.2016.06.003

72. Zentrum für Krebsregisterdaten, editor. Bericht zum Krebsgeschehen in Deutschland 2016. Berlin: Robert Koch-Institut 2016

73. Piketty $C$, Selinger-Leneman $H$, Bouvier AM et al (2012) Incidence of HIV-related anal cancer remains increased despite long-term combined antiretroviral treatment: results from the french hospital database on HIV. J Clin Oncol 30(35):4360-4366. https://doi.org/10.1200/ JCO.2012.44.5486

74. Islami F, Ferlay J, Lortet-Tieulent J et al (2017) International trends in anal cancer incidence rates. Int J Epidemiol 46(3):924-938. https:// doi.org/10.1093/ije/dyw276

75. Gatta G, Ciccolallo L, Kunkler I et al (2006) Survival from rare cancer in adults: a population-based study. Lancet Oncol 7(2):132-140. https:// doi.org/10.1016/S1470-2045(05)70471-X

76. National Cancer Institute Cancer Stat Facts: Anal Cancer 2017. https://seer.cancer.gov/statfacts/ html/anus.html. Accessed 27 Nov 2017

77. de Martel C, Plummer M, Vignat J et al (2017) Worldwide burden of cancer attributable to HPV by site, country and HPV type. Int J Cancer 
141(4):664-670. https://doi.org/10.1002/ ijc.30716

78. Jansen L, Buttmann-Schweiger N, Listl S et al (2018) Differences in incidence and survival of oral cavity and pharyngeal cancers between Germany and the United States depend on the HPV-association of the cancer site. Oral Oncol 76:8-15. https://doi.org/10.1016/j.oraloncology.2017.11.015

79. Buttmann-Schweiger N, Deleré Y, Klug SJ et al (2017) Cancer incidence in Germany attributable to human papillomavirus in 2013. BMC Cancer 17(1):682. https://doi.org/10.1186/s12885-0173678-6

80. Blomberg M, Nielsen A, Munk C et al (2011) Trends in head and neck cancer incidence in Denmark, 1978 - 2007: focus on human papillomavirus associated sites. Int J Cancer 129(3):733-741. https://doi.org/10.1002/ ijc. 25699

81. Habbous S, Chu KP, Lau H et al (2017) Human papillomavirus in oropharyngeal cancer in Canada: analysis of 5 comprehensive cancer centres using multiple imputation. CMAJ 189(32):E1030-E40. https://doi.org/10.1503/ cmaj.161379

82. Carlander AF, Gronhoj Larsen C, Jensen DH et al (2017) Continuing rise in oropharyngeal cancer in a high HPV prevalence area: A Danish population-based study from 2011 to 2014 . Eur J Cancer 70:75-82. https://doi.org/10.1016/j. ejca.2016.10.015

83. Wurdemann N, Wagner S, Sharma SJ et al (2017) Prognostic Impact of AJCC/UICC 8th Edition New Staging Rules in Oropharyngeal Squamous Cell Carcinoma. Front Oncol 7:129. https:// doi.org/10.3389/fonc.2017.00129

84. Tinhofer I, Johrens K, Keilholz U et al (2015) Contribution of human papilloma virus to the incidence of squamous cell carcinoma of the head and neck in a European population with high smoking prevalence. Eur J Cancer 51(4):514521. https://doi.org/10.1016/j.ejca.2014.12.018

85. Zentrum für Krebsregisterdaten Mundhöhlen-, Rachen- und Kehlkopfkrebs C00-14 und C32 - Erkrankungsraten nach Lokalisation 2017. www.krebsdaten.de/Krebs/DE/Content/Publikationen/Krebs_in_Deutschland/Zusatzauswertungen/Grafiken_Online/kid_2017_c00-14_ c32_lokalisation.png?_blob=publicationFile \%20und \%20KiD2017. Accessed 23 Jan 2018

86. Kraut AA, Schink T, Schulze-Rath R et al (2010) Incidence of anogenital warts in Germany: a population-based cohort study. Bmc Infect Dis 10:360. https://doi.org/10.1186/1471-2334-10360

87. Harder T, Wichmann O, Klug SJ et al (2018) Efficacy, effectiveness and safety of vaccination against human papillomavirus in males: a systematic review. BMC Med. https:// doi.org/10.1186/s12916-018-1098-3

88. Moher D, Liberati A, Tetzlaff J et al (2009) Preferred reporting items for systematic reviews and meta-analyses: the PRISMA statement. Ann Intern Med 151(4):264-269

89. Kahn JA, Rudy BJ, Xu J et al (2015) Behavioral, immunologic, and virologic correlates of oral human papillomavirus infection in HIV-infected youth. Sex Transm Dis 42(5):246-252. https:// doi.org/10.1097/OLQ.0000000000000264

90. Swedish KA, Factor SH, Goldstone SE (2012) Prevention of recurrent high-grade anal neoplasia with quadrivalent human papillomavirus vaccination of men who have sex with men: a nonconcurrent cohort study. Clin Infect Dis 54(7):891-898. https://doi.org/10.1093/cid/ cir1036

91. NCT01461096 Evaluating the effectiveness of the quadrivalent human papillomavirus (HPV) vaccine at preventing anal HPV infection in HIV-infected men and women clinicaltrials.gov. www.clinicaltrials.gov. Accessed 30 Sept 2016

92. Higgins JP, Altman DG, Gotzsche PC et al (2011) The Cochrane Collaboration's tool for assessing risk of bias in randomised trials. BMJ 343:d5928. https://doi.org/10.1136/bmj.d5928

93. Sterne JA, Hernan MA, Reeves BC et al (2016) ROBINS-I: a tool for assessing risk of bias in non-randomised studies of interventions. BMJ 355:i4919. https://doi.org/10.1136/bmj.i4919

94. Guyatt $\mathrm{GH}, \mathrm{Oxman} \mathrm{AD}$, Schunemann $\mathrm{HJ}$ et al (2011) GRADE guidelines: a new series of articles in the Journal of Clinical Epidemiology. J Clin Epidemiol 64(4):380-382. https:// doi.org/10.1016/j.jclinepi.2010.09.011

95. Guyatt GH, Oxman AD, Vist GE et al (2008) GRADE: an emerging consensus on rating quality of evidence and strength of recommendations. BMJ 336(7650):924-926. https:// doi.org/10.1136/bmj.39489.470347.AD

96. Coskuner ER, Ozkan TA, Karakose A et al (2014) Impact of the quadrivalent HPV vaccine on disease recurrence in men exposed to HPV Infection: a randomized study. J Sex Med 11(11):2785-2791. https://doi.org/10.1111/ jsm. 12670

97. Giuliano AR, Palefsky JM, Goldstone $S$ et al (2011) Efficacy of quadrivalent HPV vaccine against HPV Infection and disease in males. N Engl J Med 364(5):401-411. https:// doi.org/10.1056/NEJMoa0909537

98. Palefsky JM, Giuliano AR, Goldstone $S$ et al (2011) HPV vaccine against anal HPV infection and anal intraepithelial neoplasia. N Engl J Med 365(17):1576-1585. https://doi.org/10.1056/ NEJMoa1010971

99. Swedish KA, Goldstone SE (2014) Prevention of anal condyloma with quadrivalent human papillomavirus vaccination of older men who have sex with men. PLoS ONE 9(4):e93393. https:// doi.org/10.1371/journal.pone.0093393

100. World Health Organization Global Advisory Committee on Vaccine Safety: Safety update of HPV vaccines 2017. www.who.int/vaccine_safety/committee/topics/hpv/June_2017/en/. Accessed 27 Nov 2017

101. Deleré Y, Wichmann O, Klug SJ et al (2014) The efficacy and duration of vaccine protection against human papillomavirus: a systematic review and meta-analysis. Dtsch Arztebl Int 111(35 - 36):584-591. https://doi.org/10.3238/ arztebl.2014.0584

102. Villa LL, Costa RL, Petta CA et al (2006) High sustained efficacy of a prophylactic quadrivalent human papillomavirus types $6 / 11 / 16 / 18 \mathrm{~L} 1$ virus-like particle vaccine through 5 years of follow-up. Br J Cancer 95(11):1459-1466. https:// doi.org/10.1038/sj.bjc.6603469

103. Olsson SE, Villa LL, Costa RL et al (2007) Induction of immune memory following administration of a prophylactic quadrivalent human papillomavirus (HPV) types 6/11/16/18 L1 virus-like particle (VLP). Vaccine Vaccine 25(26):4931-4939. https://doi.org/10.1016/j. vaccine.2007.03.049
104. Drolet M, Benard E, Boily MC et al (2015) Population-level impact and herd effects following human papillomavirus vaccination programmes: a systematic review and meta-analysis. Lancet Infect Dis 15(5):565-580. https://doi.org/10.1016/ S1473-3099(14)71073-4

105. Smith MA, Liu B, Mclntyre P et al (2015) Fall in genital warts diagnoses in the general and indigenous Australian population following implementation of a national human papillomavirus vaccination program: analysis of routinely collected national hospital data. J Infect Dis 211(1):91-99. https://doi.org/10.1093/infdis/ jiu370

106. Perkins RB, Legler A, Hanchate A (2015) Trends in Male and Female Genital Warts Among Adolescents in a Safety-Net Health Care System 2004-2013: Correlation With Introduction of Female and Male Human Papillomavirus Vaccination. Sex Transm Dis 42(12):665-668. https:// doi.org/10.1097/OLQ.0000000000000369

107. Thone K, Horn J, Mikolajczyk R (2017) Evaluation of vaccination herd immunity effects for anogenital warts in a low coverage setting with human papillomavirus vaccine-an interrupted time series analysis from 2005 to 2010 using health insurance data. Bmc Infect Dis 17(1):564. https://doi.org/10.1186/s12879-017-2663-7

108. Horn J, Damm O, Kretzschmar M et al Langfristige epidemiologische und ökonomische Auswirkungen der HPV-Impfung in Deutschland 2012. www.rki.de/DE/Content/Infekt/Impfen/ Forschungsprojekte/abgeschlossene_Projekte/ HPV-Impfung/Abschlussbericht.pdf?_blob=publicationFile. Accessed: 27 Nov 2017

109. Damm O, Horn J, Mikolajczyk RT et al (2017) Cost-effectiveness of human papillomavirus vaccination in Germany. Cost Eff Resour Alloc 15:18. https://doi.org/10.1186/s12962-017-0080-9

110. Soergel P, Makowski L, Schippert $C$ et al (2012) The cost efficiency of HPV vaccines is significantly underestimated due to omission of conisation-associated prematurity with neonatal mortality and morbidity. Hum Vaccin Immunother 8(2):243-251. https://doi.org/10.4161/ hv. 18519

111. Lawton B, Howe AS, Turner N et al (2018) Association of prior HPV vaccination with reduced preterm birth: A population based study. Vaccine 36(1):134-140. https://doi.org/10.1016/j. vaccine.2017.11.020

112. Remschmidt C, Walter D, Schmich P et al (2014) Knowledge, attitude, and uptake related to human papillomavirus vaccination among young women in Germany recruited via a social media site. Hum Vaccin Immunother 10(9):2527-2535. https://doi.org/10.4161/21645515.2014.970920

113. Bundeszentrale für gesundheitliche Aufklärung Elternbefragung zum Thema Impfen im Kindesalter 2011. www.bzga.de/forschung/studien-untersuchungen/studien/impfen-und-hygiene/?sub=64. Accessed 27 Nov 2017

114. Bundeszentrale für gesundheitliche Aufklärung Einstellungen, Wissen und Verhalten der Allgemeinbevölkerung zum Infektionsschutz 2014. www.bzga.de/forschung/studien-untersuchungen/studien/impfen-und-hygiene/?sub=96. Accessed 27 Nov 2017

115. Kessels SJ, Marshall HS, Watson M et al (2012) Factors associated with HPV vaccine uptake in teenage girls: a systematic review. Vaccine 30(24):3546-3556. https://doi.org/10.1016/j. vaccine. 2012.03 .063 
116. Sturm LA, Mays RM, Zimet GD (2005) Parental beliefs and decision making about child and adolescent immunization: from polio to sexually transmitted infections. J Dev Behav Pediatr 26(6):441-452

117. Oteng B, Marra F, Lynd LD et al (2011) Evaluating societal preferences for human papillomavirus vaccine and cervical smear test screening programme. Sex Transm Infect 87(1):52-57. https:// doi.org/10.1136/sti.2009.041392

118. Rieck T, Feig M, Delere Y et al (2014) Utilization of administrative data to assess the association of an adolescent health check-up with human papillomavirus vaccine uptake in Germany. Vaccine 32(43):5564-5569. https://doi.org/10.1016/j. vaccine.2014.07.105

119. Thaiss H, Klein R, Schumann EC et al (2010) Früherkennungsuntersuchungen als Instrument im Kinderschutz. Erste Erfahrungen der Länder bei der Implementation appellativer Verfahren. Bundesgesundheitsblatt Gesundheitsforschung Gesundheitsschutz 53(10):1029-1047. https:// doi.org/10.1007/s00103-010-1134-8

120. National HPV Vaccination Program Register Australia National (Australia) HPV 3 dose vaccination coverage for adolescents turning 15 years of age 2017. www.hpvregister.org.au/research/coverage-data. Accessed 27 Nov 2017

121. Statistics Canada Childhood National Immunization Coverage Survey, 2013. www.statcan.gc.ca/ daily-quotidien/150721/dq150721c-eng.htm. Accessed 27 Nov 2017

122. Public Health England HPV vaccine coverage data for vaccinations given from 1 September 2015 to 31 August 2016 by local authority and area team 2016. www.gov.uk/government/ statistics/annual-hpv-vaccine-coverage-2015to-2016-by-local-authority-and-area-team. Accessed 27 Nov 2017

123. Folkehelseinstituttet Statistikk for HPV-vaksinasjon i barnevaksinasjonsprogrammet 2017. www. fhi.no/hn/helseregistre-og-registre/sysvak/ dekkningsstatistikk/. Accessed 27 Nov 2017

124. Folkhälsomyndigheten Statistik för HPV-vaccinationer 2016. www.folkhalsomyndigheten.se/ globalassets/statistik-uppfoljning/vaccinationsstatistik/hpv/hpv-statistik-2016-till-webbsida. pdf. Accessed 27 Nov 2017

125. Walker TY, Elam-Evans LD, Singleton JA et al (2017) National, regional, state, and selected local area vaccination coverage among adolescents aged 13 - 17 years - United States, 2016 Mmwr Morb Mortal Wkly Rep 66(33):874-882. https://doi.org/10.15585/mmwr.mm6633a2

126. Bundesamt für Gesundheit Kantonales Durchimpfungsmonitoring Schweiz 2017. www.bag.admin.ch/bag/de/home/themen/ mensch-gesundheit/uebertragbare-krankheiten/impfungen-prophylaxe/informationen-fachleute-gesundheitspersonal/durchimpfung.html. Accessed 27 Nov 2017

127. Thierry P, Lasserre A, Rossignol L et al (2016) Human Papillomavirus vaccination in general practice in France, three years after the implementation of a targeted vaccine recommendation based on age and sexual history. Hum Vaccin Immunother 12(2):528-533. https:// doi.org/10.1080/21645515.2015.1078042

128. Statens Serum Institut Human papillomavirus-vaccine (HPV) færdigvaccineret, vaccinationstilslutning 2018. www.ssi.dk/Smitteberedskab/ Sygdomsovervaagning/VaccinationSurveillance. aspx?xaxis=Cohort\&vaccination $=6 \&$ sex-
$=0 \&$ landsdel $=100 \&$ show $=\&$ datatype $=$ Vac cination\&extendedfilters=True\#HeaderText. Accessed 12 Feb 2018

129. Musto R, Siever JE, Johnston JC et al (2013) Social equity in Human Papillomavirus vaccination: a natural experiment in Calgary Canada. BMC Public Health 13:640. https:// doi.org/10.1186/1471-2458-13-640

130. Cox DS, Cox AD, Sturm L et al (2010) Behavioral interventions to increase $H P V$ vaccination acceptability among mothers of young girls. Health Psychol 29(1):29-39. https:// doi.org/10.1037/a0016942

131. Donahue K, Hendrix K, Sturm L et al (2017) Provider Communication and Mothers' Willingness to Vaccinate Against Human Papillomavirus and Influenza: A Randomized Health Messaging Trial. Acad Pediatr. https://doi.org/10.1016/j. acap.2017.07.007

132. Poethko-Muller C, Buttmann-Schweiger N, KiGGS Study Group (2014) HPV vaccination coverage in German girls: results of the KiGGS study: first follow-up (KiGGS Wave 1). Bundesgesundheitsblatt Gesundheitsforschung Gesundheitsschutz 57(7):869-877. https://doi.org/10.1007/ s00103-014-1987-3 